Ann. Biol. anim. Bioch. Biophys., I963, 3 (2), I43-190.

\title{
LES CONSTITUANTS MEMBRANAIRES DES PLANTES FOURRAGÈRES
}

\author{
R. JARRIGE
}

avec la collaboration techniqua de Marie-Thérèsa Beaufort, Jeanine Jung et Christiane Le Gallo

Station de Recherches sur l'Élenage des Ruminants, Centre national de Recherches zootechniques Jouy-en-Josas (Seine-et-Oise)

\section{SOMMAIRE}

Cette étude rapporte les variations de la teneur en constituants membranaires des feuilles, des tiges et des plantes entières des principales espèces fourragères récoltées à différents stades de déve. loppement. On a déterminé les teneurs en hémicelluloses, cellulose et lignine, de 165 échantillons d'organes séparés, de 82 échantillons de plantes entières et de 20 échantillons de foins de pré (tableau 2); on a séparé les différents polysaccharides membranaires de i 14 de ces échantillons, choisis parmi les plus représentatifs. Les résultats ne sont présentés individuellement que pour ces derniers, dans les tableaux situés en annexe (i i à 22).

Exprimées en pourcentage de la matière sèche, les teneurs en cellulose, en xylanes et en lignine ont présenté des variations très importantes avec l'organe, le stade de développement et la famille botanique ; ainsi, la teneur en cellulose a varié de $9 \mathrm{p}$. 100 pour les feuilles de légumineuses à $30-35$ p. I00 pour la plupart des tiges de graminées et de légumineuses récoltées à la floraison, et la teneur en xylanes de 2 à 2,5 p. I0o pour les feuilles de luzerne à I 8 p. Ioo en moyenne pour les inflorescences de graminées. Au contraire, les teneurs en arabanes et en hexosanes hydrolysables ont été beaucoup moins variables, et le plus souvent comprises entre 3 et $4 \mathrm{p}$. Ioo et 2 et $3,5 \mathrm{p}$. Ioo respectivement.

La composition des membranes (estimées par la somme hémicelluloses + cellulose + lignine) a également présenté des variations caractéristiques. Chez toutes les espèces étudiées, les membranes des feuilles ont contenu plus d'hémicelluloses, d'arabanes, d'hexosanes hydrolysables que les membranes des tiges, mais moins de cellulose vraie et de xylanes (le trèfle violet faisant exception à ce dernier point de vue). A stade botanique comparable, les membranes des limbes de graminées ont contenu plus de xylanes et de cellulose que celles des feuilles de légumineuses, mais moins d'hexosanes hydrolysables et de lignine. Au cours du développement, la composition des membranes est demeurée relativement constante dans les feuilles de légumineuses, de même que dans les limbes et les tiges de choux, mais elle a présenté une évolution dans toutes les autres catégories d'échantillons. Cette évolution a été très limitée pour les membranes des limbes, des gaines et même des tiges de graminées, et très importante pour les membranes des tiges de légumineuses.

\section{INTRODUCTION}

Les membranes représentent en moyenne de 30 à $40 \mathrm{p}$. Ioo de la matière sèche de l'herbe de pâture et de 45 à 55 p. Ioo de celle des foins. Elles constituent généralement la principale source d'énergie, d'abord pour la population microbienne du rumen qui 


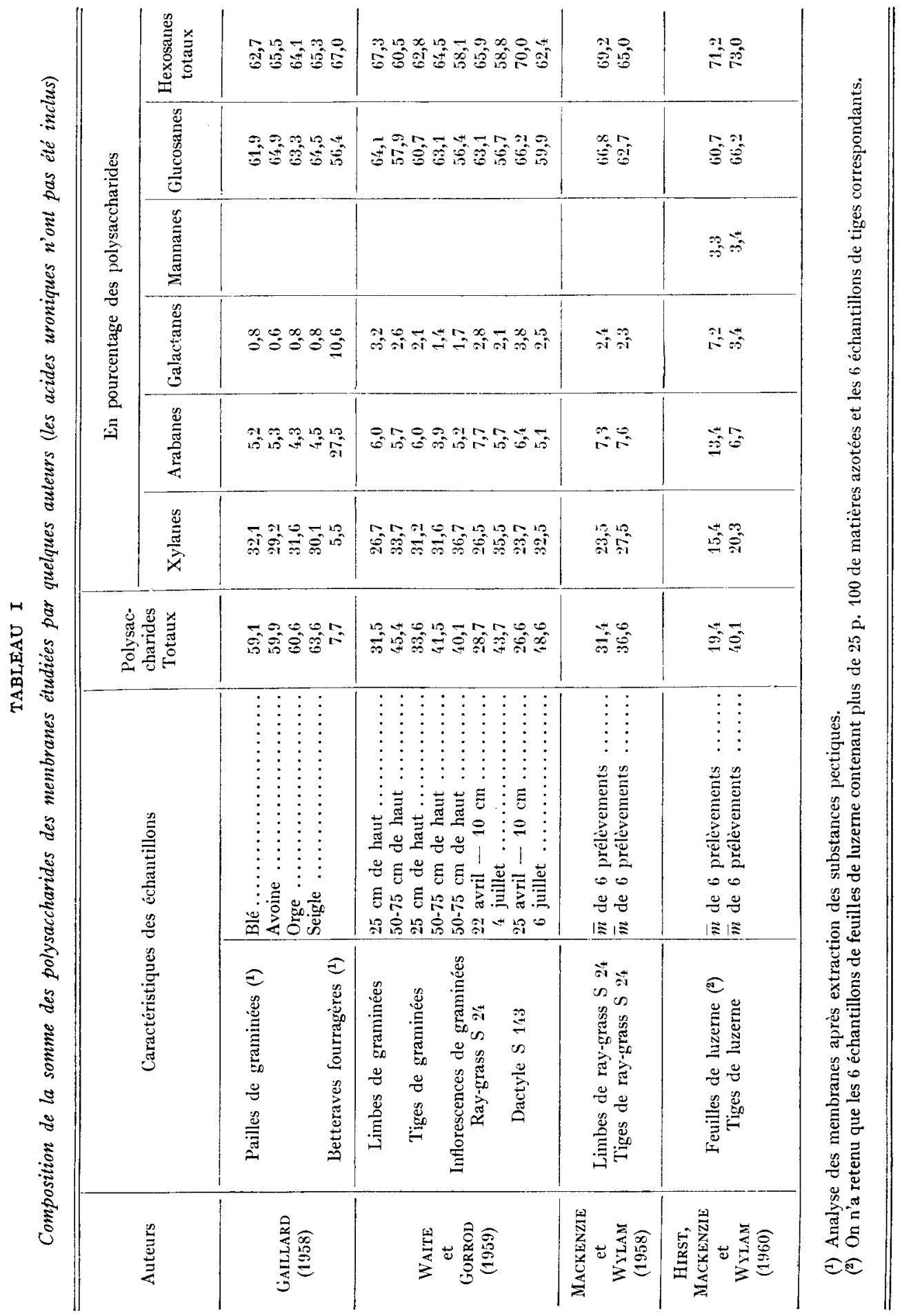


les dégrade en acides gras volatils et, ensuite, pour le ruminant qui utilise ces derniers. Il est donc nécessaire de bien connaître la teneur, et les caractéristiquesphysicochimiques des membranes pour interpréter et prévoir correctement les variations de la valeur énergétique des fourrages.

Jusqu'à ces toutes dernières années, les membranes des plantes fourragères n'avaient pas fait l'objet d'études systématiques, surtout à cause de l'insuffisance et de l'imprécision des méthodes d'analyse disponibles, notamment quant à la fraction hémicelluloses. On possédait cependant des données assez nombreuses sur les teneurs en cellulose et en lignine des principales graminées et légumineuses fourragères. (ARmstrong et al., I950 - Homb, I953 - Kivimaf, I959). Les techniques de séparation des sucres par chromatographie sur papier, ont permis récemment de mettre au point des méthodes d'analyse plus satisfaisantes, et de réaliser des progrès importants dans la connaissance des membranes (HaRwood, I954; Fauconneau et JARRIGE, I955; GaIILARD, I95 $a$-I958 $b$; MACKenzIE et WyLAM, I958 ; Hirst et al., I959; WAITE et GorRod I959 $a$-I959 $b$; JARRIGE, I960-I96I ; BATH, I960); les résultats les plus significatifs ainsi obtenus sont résumés dans le tableau $\mathrm{I}$.

Grâce à une méthode relativement rapide de fractionnement des membranes par les hydrolyses acides (JARRIGE, I96r), associé à l'analyse chromatographique des hydrolysats, nous avons pu entreprendre l'étude systématique des constituants membranaires des principales espèces fourragères dans le dessein :

a) de préciser la nature et l'importance des constituants membranaires des feuilles et des tiges (et éventuellement des inflorescences), des principales espèces fourragères aux différents stades de développement;

b) d'analyser ainsi l'influence de l'âge et de la composition morphologique sur la teneur en constituants membranaires de la plante entière :

c) de comparer la composition des membranes des principales espèces ou familles.

Nous rapportons ici l'ensemble des résultats obtenus, dont un résumé partiel a été présenté antérieurement (JARRIGE, I960).

\section{MATÉRIEI, ET MÉTHODES}

Nous avons déterminé les teneurs en hémicelluloses, cellulose et lignine, de 20 foins, de 82 échantillons de plantes entières (parties aériennes), et de $6_{5}$ échantillons d'organes (feuilles, limbes, gaines, tiges et inflorescences), des principales espèces fourragères.

Pour $8 \mathrm{I}$ échantillons d'organes et 33 échantillons de plantes entières, choisis parmi les plus représentatifs, les fractions hémicelluloses et cellulose ont fait l'objet d'une analyse chromatographique ; la nature et les caractéristiques botaniques de chacun de ces 114 échantillons sont rapportés dans les tableaux i i à 22, en même temps que la teneur des différents constituants de la membrane.

\section{ÉchanTiLLons}

Organes séparés

Les échantillons des feuilles et des tiges de luzerne (inflorescences non comprises), ont été préparés en 1955 et, surtout en 1957 (tableau I I - figure I) à partir de plantes de type Flamande, Poitou 
ou Provence, prélevées à 3 stades de développement au cours de chacun des cycles de croissance successifs.

Les échantillons de feuilles et de tiges (inflorescences non comprises) de trèfle violet Goliath (tableau 12 ), ont été préparés en 1959 à partir de prélèvements effectués au $2^{\mathrm{e}}$ cycle de croissance, lequel a eu lieu par temps très sec. C'est la même année qu'on a prélevé les 2 échantillons de trèfle blanc commun, dont on a séparé les limbes et les pétioles (tableau i 3 ).

La plupart des échantillons d'organes de graminées ont été préparés à partir de plantes prélevées à différents stades au cours du premier cycle de croissance (tableau I 8). Les plantes de ray-grass anglais récoltées en I956, ont été fractionnées en feuilles (limbes + gaines) et tiges + inflorescences ; celles du dactyle $\mathrm{S} 35$ et de fétuque des prés $\mathrm{S}_{21}$, récoltées en 1957 , ont été fractionnées en limbes, gaines, tiges et inflorescences. En 1958, 8 espèces de graminées de prairies temporaires ou permanentes ont été récoltées au début de la floraison (tableaux $\mathrm{I}_{4}$ à $\mathrm{I}_{7}$ ) : on a séparé les limbes, les gaines, les tiges et les inflorescences tels quels, sans éliminer les parties sèches.

Les échantillons de limbes et de gaines de dactyle $S_{26} 6$ présentés par la figure 3, ont été obtenus à différents stades des cycles successifs de croissance en 1958 .

Tous ces échantillons d'organes de légumineuses et de graminées ont été préparés à partir de la plante verte qu'on venait de couper et séchés à l'étuve à $70^{\circ} \mathrm{C}$ avec ventilation forcée.

L.es échantillons de limbes et de tiges de choux (tableau I9) sont des échantillons moyens préparés à partir des prélèvements journaliers (déshydratés à l'étuve à $70^{\circ} \mathrm{C}$ ) effectués au cours de la période de mesure de la digestibilité ; il faut noter qu'on a mis les pétioles ainsi que les grosses nervures avec les tiges.

\section{Plantes entières}

Les 70 échantillons de ray-grass anglais $\mathrm{S}_{24}$ (tableau 20), de dactyle $\mathrm{S}_{37}$ (tableau 21) et de trèfle blanc $\mathrm{S} 100$ (tableau $\mathrm{I}_{3}$ ) ont été prélevés au Grassland Research Institute de Hurlev en 1958 et I959 (Minson et al., 1960), à différents stades au cours du $\mathrm{r}^{\mathrm{er}}$ cycle et ensuite tous les mois ou tous les deux mois ; les plantes ont été congelées immédiatement après la récolte et l'échantillon moyen constitué aiu cours de la période de mesure de la digestibilité et séché à l'étuve.

Les I 3 échiantillons de ray-grass anglais appartenant aux populations $n^{\circ} 3$ et $n^{\circ}{ }_{2} 3$ ont été récoltés en 1954 au C. N. R. A. de Versailles (tableau 22); ro échantillons ont été prélevés à différents stades au cours du i ${ }^{\text {er }}$ cycle et 3 sur les repousses d'automne.

\section{MÉTHODES D'ANALYSE}

\section{Hydrolyses acides}

Les méthodes d'analyse utilisées ont été déjà exposées en détail (JARRIGE, I96I). Le fourrage finement broyé a d'abord été traité par l'eau au bain-marie à $40^{\circ} \mathrm{C}$ ( 2 ou 3 extractions), séché à l'étuve à $70^{\circ} \mathrm{C}$, puis dégraissé au Soxhlet par le mélange alcool-benzène $(2: \mathrm{I})$ pendant $\mathrm{I} 6$ heures.

Trois prises de 300 à $600 \mathrm{mg}$ du résidu membranaire ainsi obtenu ont été hydrolysées dans des erlenmeyers à col rodé par $\mathrm{SO}_{4} \mathrm{H}_{2} 5 \mathrm{p}$. $100\left(\mathrm{P} / \mathrm{P} / \mathrm{V} ; 20 \mathrm{~cm}^{3}\right.$ par $100 \mathrm{mg}$ de résidu) pendant 3 heures sous reflux, au bain de paraffine à $\mathrm{I} 2 \mathrm{O}^{\circ} \mathrm{C}$. L'hydrolysat a été filtré sur un buchner garni d'une rondelle tarée de papier-filtre sans cendres. Le résidu (ou lignocellulose) a été entraîné, lavé plusieurs fois par de petites quantités d'eau et finalement séché par de l'acétone.

Il a été déshydraté à l'étuve à $70^{\circ} \mathrm{C}$, pesé, séparé du papier-filtre et transféré dans un petit becher de $30 \mathrm{~cm}^{3}$ où il a été hydrolysé par $\mathrm{SO}_{4} \mathrm{H}_{2}$ à $72 \mathrm{p}$. $100\left(\mathrm{P} / p ; 2 \mathrm{~cm}^{3}\right.$ par $100 \mathrm{mg}$ de résidu) à la température de la pièce, pendant 4 heures. L'hydrolysat a été transféré dans un erlenmeyer à col rodé, étendu par 23 volumes d'eau distillée et maintenu à l'ébullition sous reflux au bain de paraffine à $120^{\circ} \mathrm{C}$ pendant 3 heures. La filtration a été effectuée comme précédemment; le résidu (lignine) lavé, séché par de l'acétone puis à l'étuve à $100^{\circ} \mathrm{C}$, a été calciné au four à $55^{\circ} \mathrm{C}$ pendant 3 heures, la perte de poids correspondant à la lignine brute. Pour $z^{\circ}$ échantillons, deux des trois résidus obtenus ont été transférés dans un matras pour déterminer leur teneur en azote par microkjeldahl.

\section{Traitement des hydrolysats}

Une partie $\left(5^{\circ} \mathrm{cm}^{3}\right.$ sur 200 ou $\left.250 \mathrm{~cm}^{3}\right)$ de chacun des trois hydrolysats " $5 \mathrm{p}$. 100" (hémicelluloses) et des trois hydrolysats " $72 \mathrm{p}$. 100 " (cellulose) de chaque échantillon a été neutralisée par $\mathrm{NaOH}$ au pHmètre. On en a dosé le pouvoir réducteur par la méthode iodométrique de SomogỸ (1952) et on 
a préparé un échantillon moyen d'hydrolysat 5 p. i oo et un échantillon moyen d'hydrolysat 72 p. Ioo pour en faire l'analyse chromatographique. Chacun d'eux a été concentré dans des capsules à l'étuve à vide $\left(40^{\circ} \mathrm{C}\right)$; les sucres ont été extraits du résidu par l'alcool a $95 \mathrm{p}$. Ioo, puis dissous par quelques $\mathrm{cm}^{3}$ d'eau bidistillée après évaporation de l'alcool ; cette solution aqueuse a été filtrée.

Les sucres ont été séparés sur papier Arches 302 ou Whatman $n^{\circ}$ I par le mélange acétate d'éthyle, acide acétique, eau (3: I : 3) (JERMYN et ISHERwoD, 1949). I.es spots (en double ou en triple pour chaque hydrolysat) ont été localisés par la révélation de bandes témoins par l'oxalate d'aniline à l'étuve à $105^{-1} 0^{\circ} \mathrm{C}$. Dans cous les cas, nous avons découpé les bandes correspondant au xylose, à l'arabinose et à l'ensemble glucose + galactose pour les hydrolysats 5 p. Ioo, au xylose et au glucose pour les hydrolysats $7^{2} \mathrm{p}$. 1 oo. Nous avons également découpé les bandes correspondant à d'autres spots lorsque ceux-ci étaient suffisamment denses ; cela est mentionné dans le texte et dans les tableaux des résultats détaillés.

Le glucose et le galactose de l'hydrolysat 5 p. 100 n'ont pas été dosés séparément parce que le galactose n'est présent qu'en faible quantité (o,5 à 3 p. Ioo des polysaccharides totaux) sauf dans les feuilles de luzerne (tableau I) et qu'il est mal séparé du glucose par le solvant utilisé. Fn revanche, ce solvant présente le gros avantage de séparer de façon rapide et satisfaisante le xylose de l'arabinose d'une part, et l'arabinose des hexoses d'autre part. Après élution, les sucres ont été dosés par la méthode colorimétrique de NELSON-SOMOGYI (I952), une courbe témoin étant établie pour chaque sucre (xylose - arabinose - glucose) pour chaque série journalière.

Pour exprimer la teneur de chaque sucre en pourcentage de la matière sèche de l'échantillon, nous avons admis que :

a) les proportions relatives de chaque sucre après séparation chromatographique sont les mêmes que dans l'hydrolysat, en d'autres termes, que les différents sucres subissent les pertes relatives semblables, au cours des différentes opérations : concentration, extraction, filtration, chromatographie, élution...

b) que les sucres dosés sont les seuls constituants réducteurs de chaque hydrolysat.

\section{Estimation de la lignine corrigée}

Dans tous les échantillons étudiés jusqu'en ig6o, c'est-à-dire la grande majorité, nous nous limitions au dosage de la lignine brute. Il est apparu que celle-ci contenait des matières azotées en quantité importante et variable qui ne permettait pas de comparer correctement la composition des membranes des organes et des plantes ayant des teneurs en natières azotées très différentes Nous avons heureusement pu montrer que la teneur en azote de la lignine brute dépendait étroitement de la teneur en azote du fourrage (JOURNET et JARRIGE, 1962) ; nous avons calculé des équations de régression permettant d'estimer avec une erreur limitée, en fonction de la teneur en azote du fourrage, soit la teneur en azote de la lignine, soit la proportion de l'azote du fourrage passant dans la lignine. De telles équations ont été établies pour les catégories de fourrages suivantes : ray-grass anglais, dactyle, ray-grass anglais et dactyle, luzerne et foins de pré.

Crrâce à elles, nous avons estimé les matières azotées de la lignine brute et la lignine corrigée des autres échantillons de ces différentes catégories analysées antérieurement; pour les échantillons de graminées autres que les ray-grass et les dactyles, nous avons utilisé la relation établie pour l'ensemble des ray-grass et des dactyles.

\section{DÉFINITION DES TERMES UTILISÉS}

Voici les termes qui ont été utilisés pour désigner les différentes fractions qui ont été exprimées, dans un premier temps, en pourcentage, de la matière sèche de l'échantillon.

Hémicelluloses (ou polyoses non cellulosiques) : $0,9 \times$ pouvoir réducteur de l'hydrolysat 5 p. Ioo (exprimé en glucose) Cette fraction contient les hexosanes hydrolysables, la majeure partie des xylanes, et la totalité des arabanes (dans la plupart des échantillons).

Cellulose : $0,9 \times$ pouvoir réducteur de l'hydrolysat $72 \mathrm{p}$. 100 (exprimé en glucose). Cette fraction contient la cellulose vraie et les xylanes résiduels.

Xylanes : 0,9 $\times$ teneur en xylose de chaque hydrolysat.

Arabanes : $0,9 \times$ teneur en arabinose de chaque hydrolysat.

Hexosanes 5. p. 100 ou hexosanes hydrolysables : $0,9 \times$ teneur en (glucose + galactose) de l'hydrolysat 5 p. 100 .

Glucosane 72 p. Ioo ou cellulose vraie : $0,9 \times$ teneur en glucose de l'hydrolysat 72 p. 100 .

Lignine (corrigée) : lignine brute $-6,25 \times$ teneur en azote de la lignine brute.

Membranes : hémicelluloses + cellulose + lignine corrigée. 


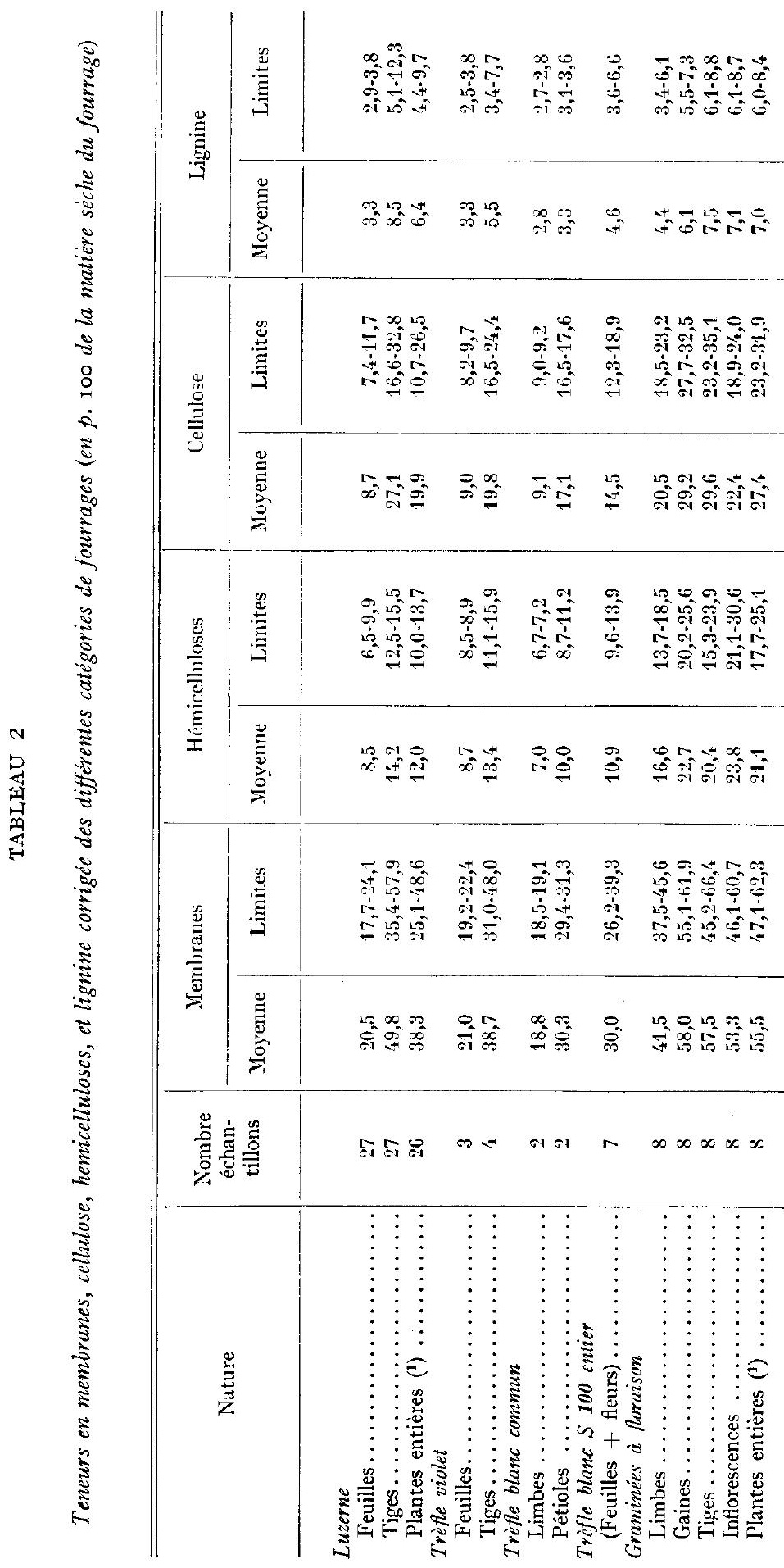




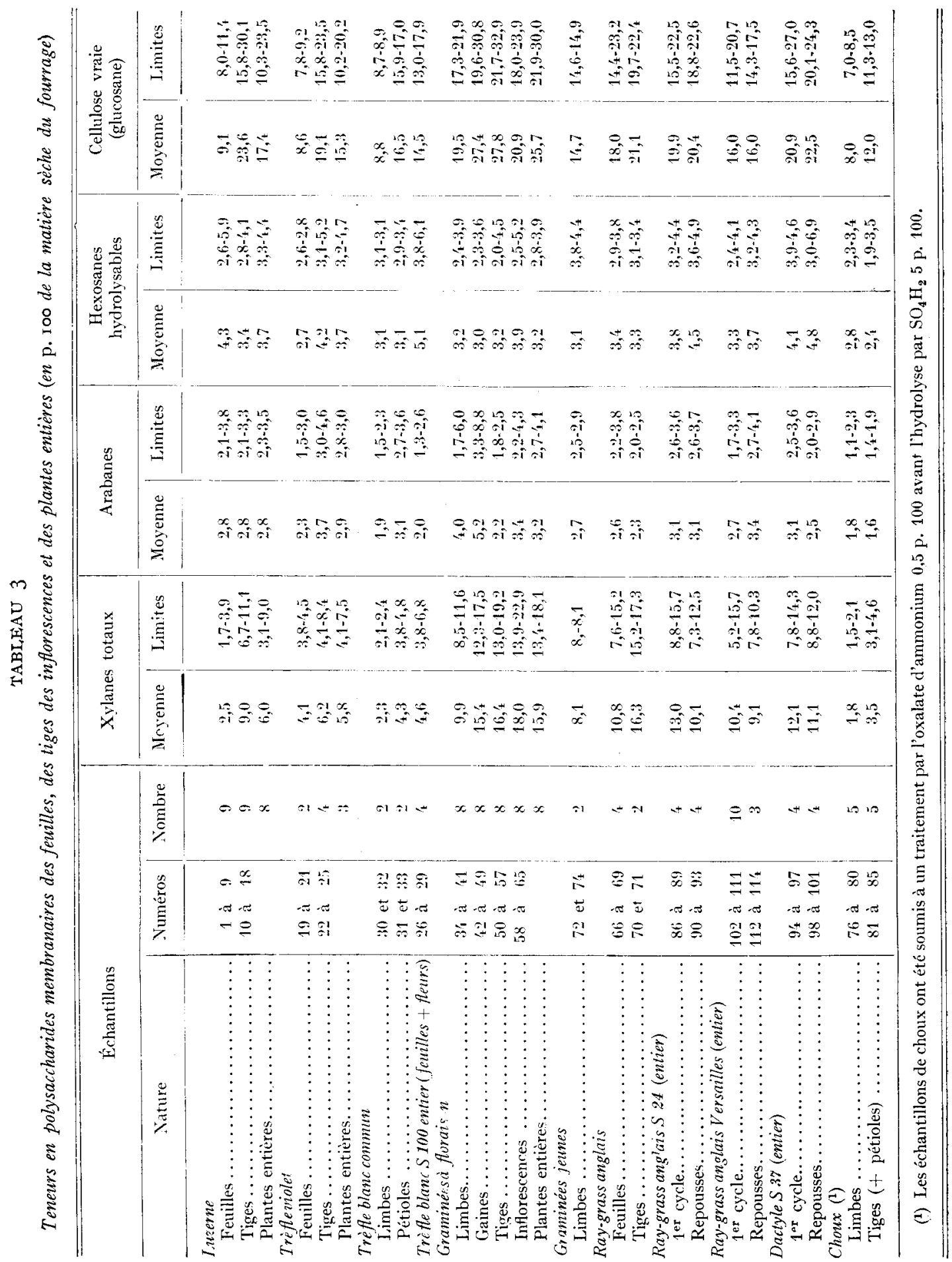




\section{RÉSUI,TATS}

\section{MOdES D'EXPRESSION DES RÉSUitats - IMPORTANCE RELATIVE DES DIFFÉRENTS CONSTITUANTS MEMBRANAIRES}

\section{En pourcentage de l'échantillon}

Nous avons d'abord exprimé les teneurs des différents constituants membranaires en pourcentage de la matière sèche de l'échantillon, comme on le fait dans toutes les études sur la composition et la valeur alimentaire des plantes fourragères. Ces teneurs ne sont reportées individuellement que pour les échantillons dont nous avons dosé séparément les différents polysaccharides (tableaux II à 22). L as teneurs en hémicelluloses, cellulose et lignine de tous les échantillons, ont été naturellement utilisées pour étudier les variations de cas constituants et sont présentées dans certaines figures. Pour chaque catégorie d'échantillons, les teneurs moyennes etextrêmes sont résumées dans le tableau 2 pour les hémicelluloses, la cellulose, la lignine et les membranes, et dans le tableau 3 pour les différents polysaccharides.

Il ressort de ces tableaux que les principaux constituants membranaires ont présenté des teneurs très différentes entre catégories d'échantillons (même sans teni $r$ compte des choux, puisqu'ils ont été "dépectinisés " par le traitement de l'oxalate d'ammonium) :

pour les hémicelluloses : de 7-9 p. roo pour les limbes ou feuilles de légumineuse s à 24 p. Ioo en moyenne pour les inflorescences des graminées récoltées à la floraison ;

pour la cellulose : de 9 p. Ioo pour les limbes ou feuilles de légumineuses à 3035 p. Ioo pour la plupart des tiges de graminées et de luzerne récoltées à la floraison ;

pour la lignine corrigée : de 2 p. Ioo pour les graminées au début du premier cycle de croissance à ro p. Ioo, ou plus, pour les tiges de luzerne récoltées à la floraison ;

pour les xylanes totaux : de 2 à à 2,5 p. Ioo pour les feuilles de luzerne ou les limbes de trèfle blanc à I 8 p. Ioo en moyenne pour les inflorescences des graminées.

En revanche, la teneur en hexosanes hydrolysables a été relativement peu variable (tableau 3), et le plus souvent comprise entre 3 et 4 p. Ioo. De même, la teneur en arabanes, n'a varié que de $2 \mathrm{p}$. Ioo pour les échantillons de trèfle blanc, à $5 \mathrm{p}$. Ioo pour les gaines de graminées ; elle a été généralement de 2 à 3 p. Ioo pour les légumineuses entières, et de 2,5 à 3,5 p. Ioo pour les graminées entières.

Au total, la proportion des membranes dans la matièra sèche a varié de $20 \mathrm{p}$. Ioo en moyenne pour les feuilles de légumineuses à plus de $60 \mathrm{p}$. Ioo pour certains échantillons de gaines et de tiges de graminées récoltées à la floraison.

\section{En pourcentage des membranes}

Pour étudier la composition des membranes et comparer des échantillons ayant des teneurs en membranes très différentes, il faut exprimer la teneur de chaque constituant non plus en pourcentage de l'échantillon, mais en pourcentage des membranes. C'est ce que nous avons donc fait pour chaque échantillon, en admettant que les membranes pouvaient être représentées, en première approximation, par la somme 
Composition moyenne des membranes des feuilles, des tiges, des inforescences et des plar

\begin{tabular}{|c|c|c|c|c|}
\hline \multicolumn{3}{|l|}{ Échantillons } & \multirow{2}{*}{$\begin{array}{l}\text { Membranes } \\
\text { ( } \% \text { de la } \\
\text { matière sèche) }\end{array}$} & \multirow{2}{*}{$\begin{array}{l}\text { Lignine } \\
(\% \text { des } \\
\text { membranes) }\end{array}$} \\
\hline Nature & Numéros & Nombre & & \\
\hline \multicolumn{5}{|l|}{ Luzerne } \\
\hline 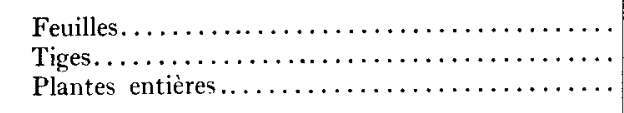 & $\begin{array}{rrr}1 & \text { à } & 9 \\
10 & \text { à } & 18\end{array}$ & $\begin{array}{l}9 \\
9 \\
8\end{array}$ & $\begin{array}{l}22,3 \\
47,2 \\
36,1\end{array}$ & $\begin{array}{l}16,4 \pm 2,3 \\
17,4 \pm 2,3 \\
16,9\end{array}$ \\
\hline \multicolumn{5}{|l|}{ Trèfle violet } \\
\hline 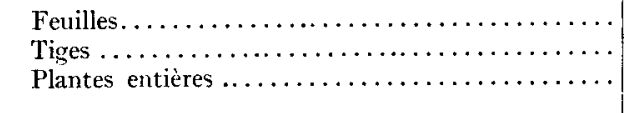 & $\begin{array}{lll}19 & \grave{a} & 21 \\
22 & \grave{a} & 25\end{array}$ & $\begin{array}{l}3 \\
4 \\
3\end{array}$ & $\begin{array}{l}21,0 \\
38,6 \\
33,2\end{array}$ & $\begin{array}{l}15,7 \\
13,7 \\
16,0\end{array}$ \\
\hline \multicolumn{5}{|l|}{ Trèfle blanc commun } \\
\hline 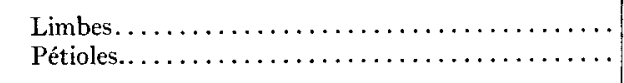 & $\begin{array}{l}30 \text { et } 32 \\
31 \text { et } 33\end{array}$ & $\begin{array}{l}2 \\
2\end{array}$ & $\begin{array}{l}18,8 \\
30,3\end{array}$ & $\begin{array}{l}14,7 \\
11,9\end{array}$ \\
\hline Trèfle blanc $S 100$ entier (feuilles + fleurs)........... & $26 \dot{\mathrm{a}} \quad 29$ & 4 & 30,9 & 15,1 \\
\hline \multicolumn{5}{|l|}{ Graminees à fioraison } \\
\hline 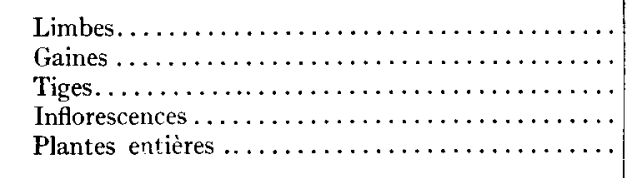 & $\begin{array}{lll}3 \prime & \text { à } & 41 \\
42 & \text { à } & 49 \\
50 & \text { à } & 57 \\
58 & \text { à } & 65\end{array}$ & $\begin{array}{l}8 \\
8 \\
8 \\
8 \\
8\end{array}$ & $\begin{array}{l}41,5 \\
57,9 \\
57,5 \\
53,4 \\
55,5\end{array}$ & $\begin{array}{l}10,7 \pm 2,3 \\
10,5 \pm 1,2 \\
13,2 \pm 1,4 \\
13,3 \pm 2,5 \\
12,6\end{array}$ \\
\hline \multicolumn{5}{|l|}{ Graminées jeunes } \\
\hline Limbes.................................. & 72 à $7 \mathbf{n}$ & 2 & 34,0 & 10,0 \\
\hline \multicolumn{5}{|l|}{ Ray-grass anglais } \\
\hline 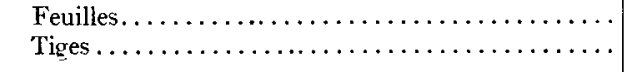 & $\begin{array}{cc}66 \text { à } & 69 \\
70 \text { et } & 71\end{array}$ & $\begin{array}{l}4 \\
2\end{array}$ & $\begin{array}{l}38,7 \\
49,6\end{array}$ & $\begin{array}{l}10,0 \\
13,5\end{array}$ \\
\hline \multicolumn{5}{|l|}{ Ray-grass anglais $S 24$ (entier) } \\
\hline 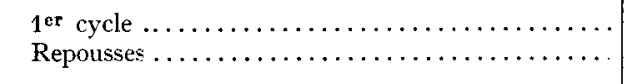 & $\begin{array}{lll}86 & \text { à } & 89 \\
90 & \text { à } & 93\end{array}$ & $\begin{array}{l}4 \\
4\end{array}$ & $\begin{array}{l}14,2 \\
42,0\end{array}$ & $\begin{array}{l}9,9 \\
9,4\end{array}$ \\
\hline \multicolumn{5}{|l|}{ Ray grass anglais I"ersailles (entier) } \\
\hline 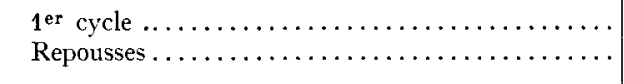 & $\begin{array}{l}102 \text { à } 111 \\
112 \text { à } 114\end{array}$ & $\begin{array}{r}10 \\
3\end{array}$ & $\begin{array}{l}36,8 \\
36,9\end{array}$ & $\begin{array}{l}11,6 \\
13.0\end{array}$ \\
\hline \multicolumn{5}{|l|}{ Dactyle: 537 (entier) } \\
\hline 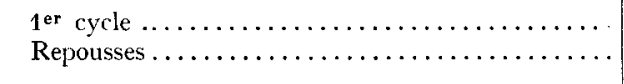 & $\begin{array}{rrr}94 & \grave{a} & 97 \\
98 & \grave{a} & 101\end{array}$ & 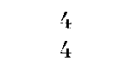 & 45,2 & $\begin{array}{l}10,8 \\
12,2\end{array}$ \\
\hline \multicolumn{5}{|l|}{ Choux $\left({ }^{1}\right)$} \\
\hline 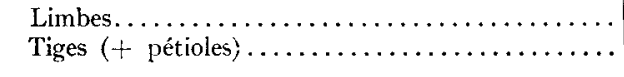 & $\begin{array}{lll}76 & \text { à } & 80 \\
81 & \text { à } & 85\end{array}$ & $\begin{array}{l}5 \\
5\end{array}$ & $\begin{array}{l}17,1 \\
22,0\end{array}$ & $\begin{array}{l}15,2 \pm 2,0 \\
10,8 \pm 1,5\end{array}$ \\
\hline
\end{tabular}

(') Les échantillons de choux ont été soumis à un traitement par l'oxalate d'ammonium $0.5 \%$ avant l'hydrolyse par 
hémicelluloses + cellulose + lignine corrigée, hypothèse qui sera discutée ultérieurement. Les teneurs moyennes ainsi calculées pour chaque catégorie d'échantillons sont rassemblées dans le tableau 4; elles permettent de situer l'importance respective des constituants de la membranes.

La cellulose vraie a toujours été le constituant le plus important dans tous les échantillons; elle a représenté approximativement $45 \mathrm{p}$. roo des membranes des plantes entières, cette proportion variant de $40 \mathrm{p}$. Ioo pour les feuilles de légumineuses et les inflorescences de graminées, à 55 p. Ioo pour les tiges ( + pétioles) de choux et les pétioles de trèfle blanc. La fraction cellulose (cellulose + xylanes résiduels) a représenté en moyenne $47 \mathrm{p}$. Ioo des membranes des 20 foins de prairie à flore complexe. On peut considérer cette valeur comme une moyenne générale puisque ces foins avaient une composition botanique très variable. La teneur en cellulose apparaît donc comme un critère satisfaisant de la teneur en membranes des plantes entières ; elle permet de comparer à ce point de vù des plantes appartenant à des familles différentes.

Après la cellulose, les xylanes ont été les polysaccharides membranaires les plus importants de toutes les plantes entières étudiées, à l'exception des échantillons de trèfle blanc; chez ces derniers, ils ont été moins importants que les hexosanes hydrolysables, de même que dans les autres feuilleś de légumineuses et dans les limbes de choux. Ils ont été aussi les polysaccharides les plus variables puisque leur proportion dans les membranes a varié de $12 \mathrm{p}$. Ioo pour les feuilles de luzerne et de trèfle blanc, à 33 p. roo environ pour les inflorescences de graminées.

La teneur des membranes en hexosanes hydrolysables a été, elle aussi, très variable : 5-6 p. Ioo pour les tiges et les gaines des graminées récoltées à la floraison, à I9 p. Ioo pour les feuilles de luzerne. D'une façon très générale elle a varié en sens inverse de la proportion de membranes dans l'échantillon. Les hexosanes hydrolysables ont représenté une fraction également très variable des hexosanes totaux (tableau 5) : de ro p. Ioo pour les gaines et les tiges des graminées récoltées à la flo raison, à $30 \mathrm{p}$. Ioo pour les feuilles de luzerne.

La teneur des membranes en arabanes a varié approximativement dans le mêmesens que la teneur en hexosanes hydrolysables, de $4 \mathrm{p}$. Ioo pour les tiges des graminées récoltées à la floraison, à 12 p. Ioo pour les feuilles de luzerne. Elle a été plus faible que la teneur en hexosanes hydrolysables dans la plupart des plantes entières.

La teneur des membranes en lignine a varié de 5 à I7 p. Ioo pour l'ensemble des échantillons d'organes et de plantes entières de graminées, et de Io à $2 \mathrm{I}$ p. Ioo pour l'ensemble des échantillons d'organes de légumineuses. Quant aux teneurs moyennes des différentes catégories d'échantillons (tableau 4), elles ont été comprises entre ro et $\mathrm{r} 7 \mathrm{p}$. roo.

Les deux modes d'expression de la teneur des constituants membranaires, amènent à des constatations parfois très différentes ; par exemple, en pourcentage de la matière sèche, la teneur en cellulose apparait très variable et la teneur en hexosanes hydrolysables relativement constante ; au contraire, en pourcentage des membranes, la teneur en cellulose devient baaucoup moins variable que la teneur en hexosanes hydrolysables. La figure I permet de comparer les deux modes d'expression dans le cas des tiges de luzerne.

Nous utiliserons ces deux modes d'expressions dans l'exposé détaillé des résultats. pour étudier la composition des membranes des feuilles et tiges des principales es- 
pèces fourragères, objet principal de ce travail, nous exprimerons obligatoirement les teneurs des constituants membranaires en pourcentage des membranes. Au contraire, pour les plantes entières, nous les exprimerons de préférence en pourcentage
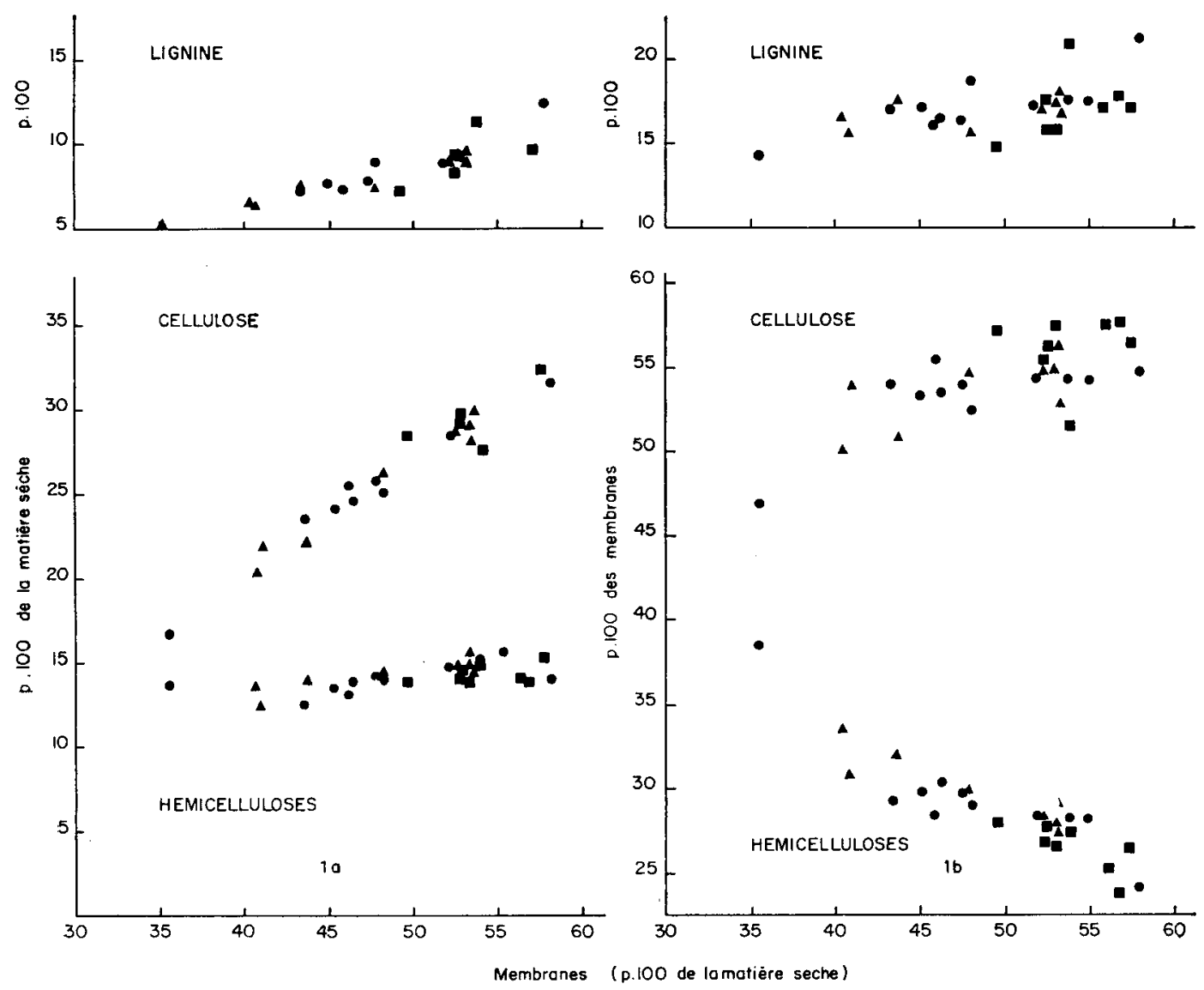

FIG. I. - Comparaison entre les modes d'expression des constituants membranaires des tiges de luzerne, en pourcentage de la matière sèche (I a) et en pourcentage des membranes (i $b$ )

- ier cycle $2^{e}$ cycle $\Delta 3^{e}$ et $4^{\text {e }}$ cycle

de la matière sèche, puisque nous chercherons surtout à dégager des relations entre les teneurs des différents constituants, et la teneur en membranes.

On peut enfin exprimer les teneurs en polysaccharides de la membrane en fonction des polysaccharides totaux de la membrane, c'est-à-dire de la somme: hémicelluloses + cellulose. C'est ce que nous avons fait dans le tableau 5 pour les différentes catégories d'échantillons, afin de comparer nos résultats à ceux obtenus par les autres auteurs (tableau I) qui, soit n'ont pas déterminé la lignine, soit l'ont dosée par des méthođes différant de celle que nous avons utilisée. 


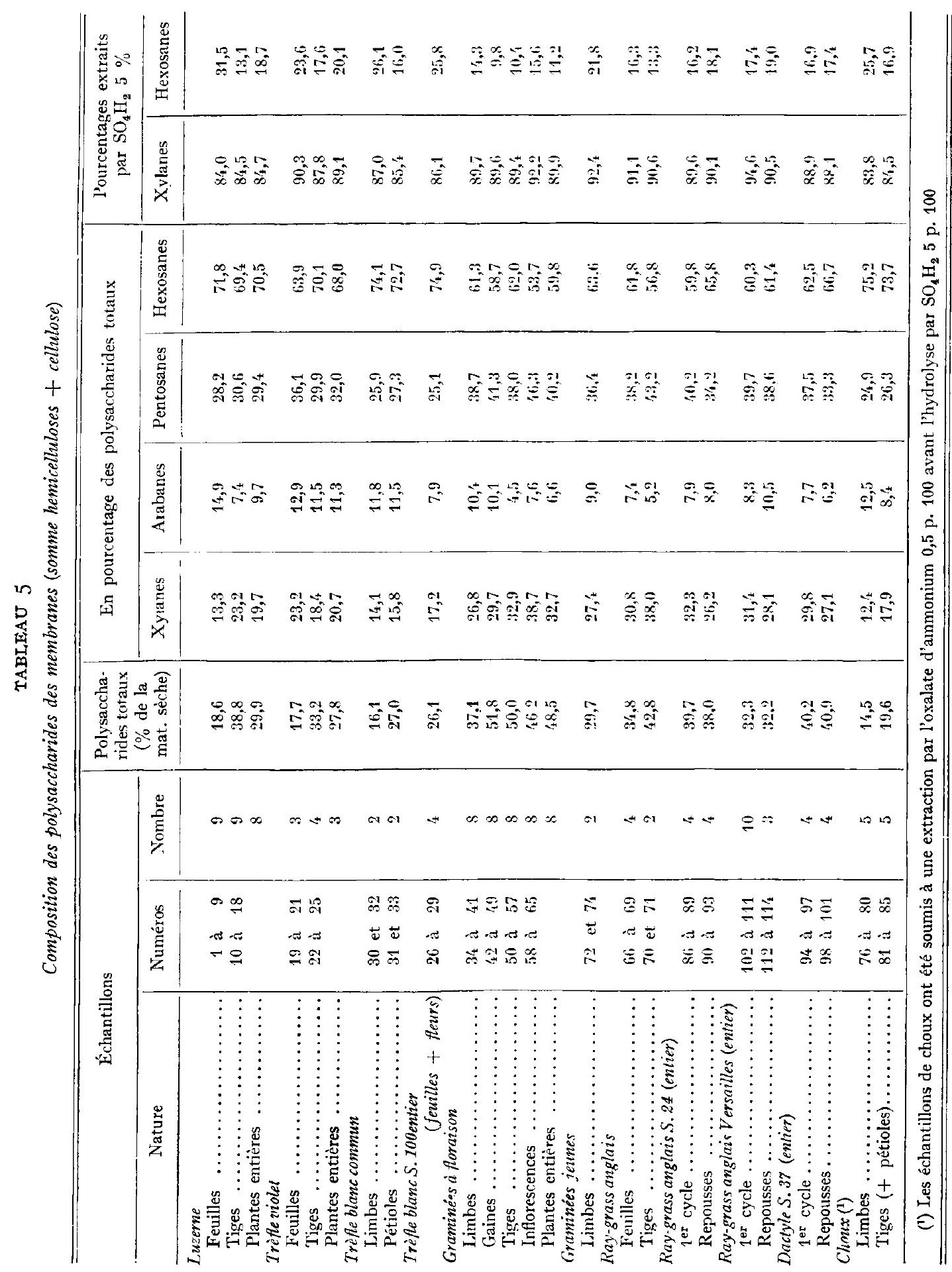




\section{FEUII,LES ET TIGES}

\section{Luzerne.}

\section{Légumineuses}

Fenilles. - Les 27 feuilles de luzerne étudiées ont présenté une teneur faible et assez constante de constituants membranaires : en moyenne $8,80 \mathrm{p}$. IOO $\pm 0,90$ d'hémicelluloses, 8,69 p. Ioo $\pm 0,89$ de cellulose, 3,3I p. Ioo $\pm 0,5$ I de lignine et 20,80 p. $100 \pm 1,68$ de membranes. Leurs membranes ont donc eu une composition relativement peu variable $: 42,4$ p. Ioo $\pm 3,37$ d'hémicelluloses, $4 \mathrm{I}, 8 \mathrm{p}$. IO0 $\pm 3,08 \mathrm{de}$ cellulose et $\mathrm{I} 5,8$ p roo $\pm \mathrm{I}, 74$ de lignine.

Elles sont caractérisées (tableau I I) par leur faible teneur en cellulose vraie et en xylanes et leur richesse en arabanes et en hexosanes hydrolysables, ces derniers représentant en moyenne $3 \mathrm{I}, 5 \mathrm{p}$. Ioo des hexosanes totaux; corrélativement leur fraction hémicelluloses est riche en arabanes et hexosanes hydrolysables. La composition de ces membranes a présenté cependant certaines variations qui n'ont pas été suffisamment systématiques pour être attribuées à l'influence de l'âge, du numéro du cycle de croissance de 1'année ou de la variété. HIRst et al. (1959) en ont observé de beaucoup plus importantes, notainment dans les proportions de glucosane hydrolysable et de cellulose vraie; elles pourraient être dues en majeure partie au fait que ces auteurs ont limité les traitements préliminaires à une extraction par l'alcool 80 p. Ioo, dont nous avons montré parailleurs l'insuffisance et les effets.perturbateurs sur l'hydrolyse ultérieure des hexosanes, tout particulièrement pour les feuilles de légumineuse (JARRIGE, I96I).

Tiges. - Les teneurs en cellulose, en lignine et en membranes des 27 échantillons de tiges de luzerne étudiés ont varié dans des limites très larges (de 35 à $5^{8} \mathrm{p}$. Ioo pour les membranes) (figure $I$ ) et ont augmenté au cours de chacun des cycles de croissance. Il n'en a pas été de même pour la teneur en hémicelluloses qui n'a augmenté que très peu avee l'âge, ne passant pratiquement que de I3-I4 p. Ioo à I4-I6 p. IOO quand la teneur en membranes s'élevait de 35-40 p. Ioo à $55 \mathrm{p}$. Ioo.

Par suite, la composition des membranes des tiges a présenté une évolution régulière avec l'âge, très semblable au cours de différents cycles decroissance (figure $\mathrm{r}$ ) : leurs teneurs en cellulose et en lignineontaugmentéalors queleur teneur en hémicelluloses diminuait; plus précisément ce sont les teneurs en arabanes et hexosanes hydrolysables qui ont diminué car la teneur en xylanes est demeurée presque constante(r6,2 p. roo dans les hémicelluloses, r9,2 p. Ioo au total). La lignine a augmenté légèrement plus vite que la cellulose, le rapport lignine/cellulose étant en moyenne de l'ordre de $0,3 \mathbf{I}$. A importance égale dans les tiges, les membranes du $2^{\mathrm{e}}$ cycle de croissance ont été sensiblement plus riches en cellulose que celles du I ${ }^{\text {er }}$ cycle (figure $I b$ ).

Les membranes des tiges ont une composition très différente de celle des membranes des feuilles correspondantes (tableau II) : elles sont beaucoup plus riches en cellulose $(54,2$ p. Ioo au lieu d : 4r,9 p. roo pour les 27 échantillons), en cellulose vraie et en xylanes et plu: pauvres en hémicelluloses, arabanes et hexosanes hydrolysables (en moyenne $\mathrm{r}_{4}, 5 \mathrm{p}$. roo des hexosane; totaux), ces différences s'accroissant pour la plupart avec l'âge ; elles sont légèrement plus riches en lignine. 
Ces données sont en bon accord avec celles obtenues par HrRst et al. (I959) sur les tiges de la luzerne du Puits, qu'elles soient rapportées à l'échantillon ou à la somme des polysaccharides de la membrane (comparer les tableaux I et 5).

Type. - Les membranes ont présentè une concentration significativement plus élevée $(\mathrm{P}<0,05)$ dans les luzernes Flamande que dans les luzernes du Poitou à la fois dans les tiges et dans les feuilles; en revanche elles ont eu pratiquement la même composition dans les deux types. Cette comparaison, dont le tableau 6 donne les résultats, a été effectuée sur 8 échantillons de chaque type, cultivés et prélevés dans les mêmes conditions : 3 ont été prélevés cours du Ier cycle, 3 au cours du $2^{\mathrm{e}}$ cycle, I au $3^{\mathrm{e}}$ et I au $4^{\mathrm{e}}$ cycle.

\section{TABLEAU 6}

Composition comparée des membranes de la luzerne Flamande et de la luzerne du Poitou

\begin{tabular}{|c|c|c|c|c|c|}
\hline & \multirow{2}{*}{$\begin{array}{c}\text { Nombre } \\
\text { d'échantillons }\end{array}$} & \multirow{2}{*}{$\begin{array}{c}\text { Membranes }(\% \\
\text { de la } \\
\text { matière sèche) }\end{array}$} & \multicolumn{3}{|c|}{ En pourcentage des membranes } \\
\hline & & & Hemicelluloses & Cellulose & Lignine \\
\hline \multicolumn{6}{|l|}{ Tiges } \\
\hline Flamande.. & 8 & 52,0 & 27,9 & 55,2 & 16,9 \\
\hline Poitou. ........ & 8 & 49,1 & 28,5 & 54,9 & 16,7 \\
\hline Feuilles & & & & & \\
\hline Flamande....... & 8 & 21,0 & 42,6 & 42,2 & 15,2 \\
\hline Poitou ........ & 8 & 19,6 & 11,8 & 42,2 & 16,0 \\
\hline
\end{tabular}

\section{Trèfle violet.}

Les données obtenues sur le trèfle violet Goliath sont moins sûres que celles obtenues sur la luzerne, d'abord parce que nous n'avons étudié qu'un petit nombre d'échantillons et, ensuite, parce que les hydrolysats par $\mathrm{SO}_{4} \mathrm{H}_{2} 5 \mathrm{p}$. Ioo contenait un certain nombre de produits que nous n'avons pas identifiés ni dosés. Ils donnaient sur les chromatogrammes des spots bien caractérisés, aussi bien pour les feuilles que pour les tiges, d'une part en avant du xylose ( $r$ à 3), d'autre part entre l'arabinose et le glucose ( $\mathrm{I}$ à 2) ainsi qu'en arrière du galactose dans certains échantillons.

Les membranes n'ont représenté qu'une faible proportion (2I,I p. Ioo) des 3 échantillons de feuilles étudiés, prélevés à différents stades au cours du $2^{\mathrm{e}}$ cycle de croissance (tableau I2). Comparées à celles des feuilles de luzerne, elles ont eu sensiblement la même teneur faible en cellulose (4r, I p. Ioo de cellulose vraie) mais elles ont été beaucoup plus riches en xylanes et plus pauvres en hexosanes hydrolysables; elles ont ainsi contenu plus de xylanes que les membranes des tiges (ce qui est une exception par rapport à toutes les autres espèces étudiées). Ces dernières ont en revanche contenu beaucoup plus de cellulose (49,4 p. Ioo de cellulose vraie) moins d'hémicelluloses et aussi moins de lignine que celles des feuilles.

En même temps que leur importance augmentait dans les tiges au cours du $2^{\mathrm{e}}$ cycle de croissance, les membranes ont subi une évolution dans leur composition : leur teneur en cellulose et en lignine a augmenté et leur teneur en hémicelluloses, en arabanes et en hexosanes hydrolysables a diminué. Cette évolution a donc été très comparable à celle observée pour les tiges de luzerne (figure I). 
Trèfle blanc.

Les limbes des deux échantillons de trèfle blanc commun ont contenu beaucoup moins de membranes que les pétioles correspondants : I8,8 p. Ioo au lieu de 30,3 p. Ioo. Leurs membranes ont été pauvres en xylanes et riches en hexosanes hydrolysables (tableau I3), donc plus proches de celles de la luzerne que de celles du trèfle violet, mais elles ont été baaucoup plus riches en cellulose vraie (46,8 p. Ioo). Les membranes des pétioles ont eu des teneurs en xylanes et en arabanes comparables à celles des limbes mais elles ont contenu nettement plus de cellulose et moins d'hexosanes hydrolysables et de lignine.

Les 4 échantillons de trèfle blanc $S$ roo récoltés d'août à novembre ont eu sensiblement les mêmes teneurs en constituants membranaires, indépendamment de leur âge : en moyenne 9,8 p. Ioo d'hémicelluloses, r2,9 p. roo de cellulose, 4,o p. roo de lignine et $27,6 \mathrm{p}$. Ios de membranes (tableau r3). Les 3 échantillons prélevés en juin et juillet en ont contenu plus (29,7 à 39,3 p. Ioo de membranes) peut-être parce qu'ils étaient en fleurs. Les membranes de ces 7 échantillons ont eu cependant une composition relativement peu variable, voisine de celle des membranes des limbes de trèfle blanc commun : 36,4 p. Ioo \pm I, Io d'hémicelluloses, 48,4 p. Ioo \pm r,25 de cellulose $\mathrm{I}_{5,3}$ p. IOO $\pm \mathrm{I}, 08$ de lignine.

\section{Graminées}

\section{A la floraison.}

Dans les huit espèces de graminées récoltées à la floraison du $\mathrm{I}^{\text {er }}$ cycle en $\mathrm{I958}$, les membranes ont représenté en moyenne $4 \mathrm{I}, 5 \mathrm{p}$. Ioo (de la matière sèche) des limbes (tableau I4), 57,9 p. roo des gaines (tableau I5), 57,5 p. roo des tiges (tableau I6) et $53,3 \mathrm{p}$. Ioo des inflorescences (tableau $\mathrm{I} 7$ ).

Elles ont présenté entre ces organes des différences de composition systématiques, beaucoup plus limitées cependant que celles observées jusqu'ici entre les feuilles et les tiges de légumineuses. Les membranes des limbes ont contenu plus d'hémicelluloses (39,9 au lietu de 35,5 p. Ioo), d'arabanes et d'hexosanes hydrolysables que celles des tiges mais moins de xylanes et de lignine, toutes ces différences étant significatives $(P<0,05)$; elles ont contenu également un peu moins de cellulose.

Les membranes des gaines ont eu une composition voisine de celles des limbes avec lesquelles elles n'ont présenté aucune différence significative ; elles ont cependant eu une teneur en xylanes plus élevée sauf dans la flouve et dans la houlque. Elles se sont par-là rapprochées des membranes des tiges mais elles ont contenu significativement plus d'arabanes et moins de lignine (I0,5 p. Ioo au lieu de 13,2 p. IOO) que celles-ci.

Les membranes des inflorescences ont présenté une composition très particulière (tableau I7), caractérisée d'abord par une teneur en cellulose vraie (39,3 p. Ioo) beaucoup plus faible que celle des autres organes (voisine de celle observée dans les membranes des feuilles de la luzerne et du trèfle violet) et ensuite, par une forte teneur en xylanes : 33,5 p. Ioo au total, ca qui est la valeur de beaucoup la plus élevée que nous ayons observée jusqu'ici. Les membranes des inflorescences ont eu par ailleurs des teneurs en arabanes, hexosanes hydrolysables et lignine comparables à celle des tiges. Ces données sont en excellent accord avec celles obtenues par WAITE 
et GorRoD (I959) avec des méthodes différentes (comparer tableau I et tableau 5).

D'autres échantillons de tiges récoltés à floraison ont été étudiés séparément (tableau $\mathrm{x} 8$ ) ; les deux tiges de dactyle et de fétuque, dont on avait enlevé les inflorescences, ont eu sensiblement la même composition que les précédentes. Au contraire les tiges de ray-grass anglais ont contenu nettement plus de xylanes et moins de cellulose parce qu'on n'en avait pas séparé les inflorescences.

Les chromatogrammes des hydrolysats $5 \mathrm{p}$. Ioo de la plupart des échantillons prélevés au début de la floraison ont présenté en plus du galactose, du glucose, de l'arabinose et du xylose, plusieurs autres spots que nous n'avions pas observés de façon aussi fréquente dans les autres échantillons d'organes ou de plantes entières de graminées :

a) Un spot rose (à la révélation par l'oxalate d'aniline) en arrière des hexoses plus fréquent dans les tiges et les inflorescences.

b) Un $2^{\mathrm{e}}$ spot rose situé entre le glucose et le mannose, très fréquent sauf dans les inflorescences.

c) Un spot qui doit être du mannose, présent dans la plupart des limbes et des inflorescences, mais non dans les gaines et les tiges.

d) Un $3^{\mathbf{e}}$ spot situé en avant du xylose, ayant par rapport à ce dernier un $\mathrm{R} x$ de $I, 30$, présent dans la majorité des limbes, gaines et tiges.

e) Un $4^{\mathrm{e}}$ spot rose ayant par rapport au xylose un $\mathrm{R} x$ de $\mathrm{I}, 5^{\circ}$ présent dans la plupart des gaines et absent des inflorescences.

Seuls ces 2 derniers ont été présents en quantités suffisamment importantes ; ils ont été dosés séparément et reportés en commun sur les tableaux sous le terme de "autres pentosanes".

Sur les chromatogrammes des hydrolysats $72 \mathrm{p}$. Ioo on n'a que très rarement observé les spots roses $a, b, c, d$ et $e$, à l'exception du spot $a$ qui a été présent dans presque toutes les inflorescences. On a noté en revanche la présence de deux spots jaunes en arrière du galactose dans les limbes, les gaines et les tiges et d'un seul dans les inflorescences. Les limbes, les gaines et les inflorescences ont présenté un spot de mannose, plus intense dans les gaines.

\section{Évolution au cours $d u \mathrm{I}^{\mathrm{er}}$ cycle.}

Les données observées sur les prélèvements échelonnés de ray-grass anglais, de fétuque et de dactyle (tableau I 8 - figure 2 ) montrent qu'au cours du I ${ }^{\text {er }}$ cycle la proportion des membranes augmente simultanément dans les limbes, les gaines et les tiges et que la composition de ces membranes évolue en raison de la lignification.

Très faible au début de la croissance ( 5 à $7 \mathrm{p}$. Ioo), la teneur en lignine des membranes a augmenté de façon importante aussi bien dans les limbes que dans les gaines où elle a doublé (figure 2). Cette augmentation a été plus rapide au stade feuillu chez le dactyle, et à partir de l'épiaison chez la fétuque ; elle s'est effectuée plutôt au détriment de la teneur en cellulose dans les membranes des limbes mais exclusivement au détriment de la teneur en hémicelluloses dans les membranes de gaines. Nous n'avons malheureusement pas fait l'analyse chromatographique d'un nombre d'échantillons suffisant pour pouvoir préciser la nature des polysaccharides auxquels est due cette évolution ; il apparaît cependant que la proportion d'hexosanes hydrolysables diminue dans les membranes des limbes. 

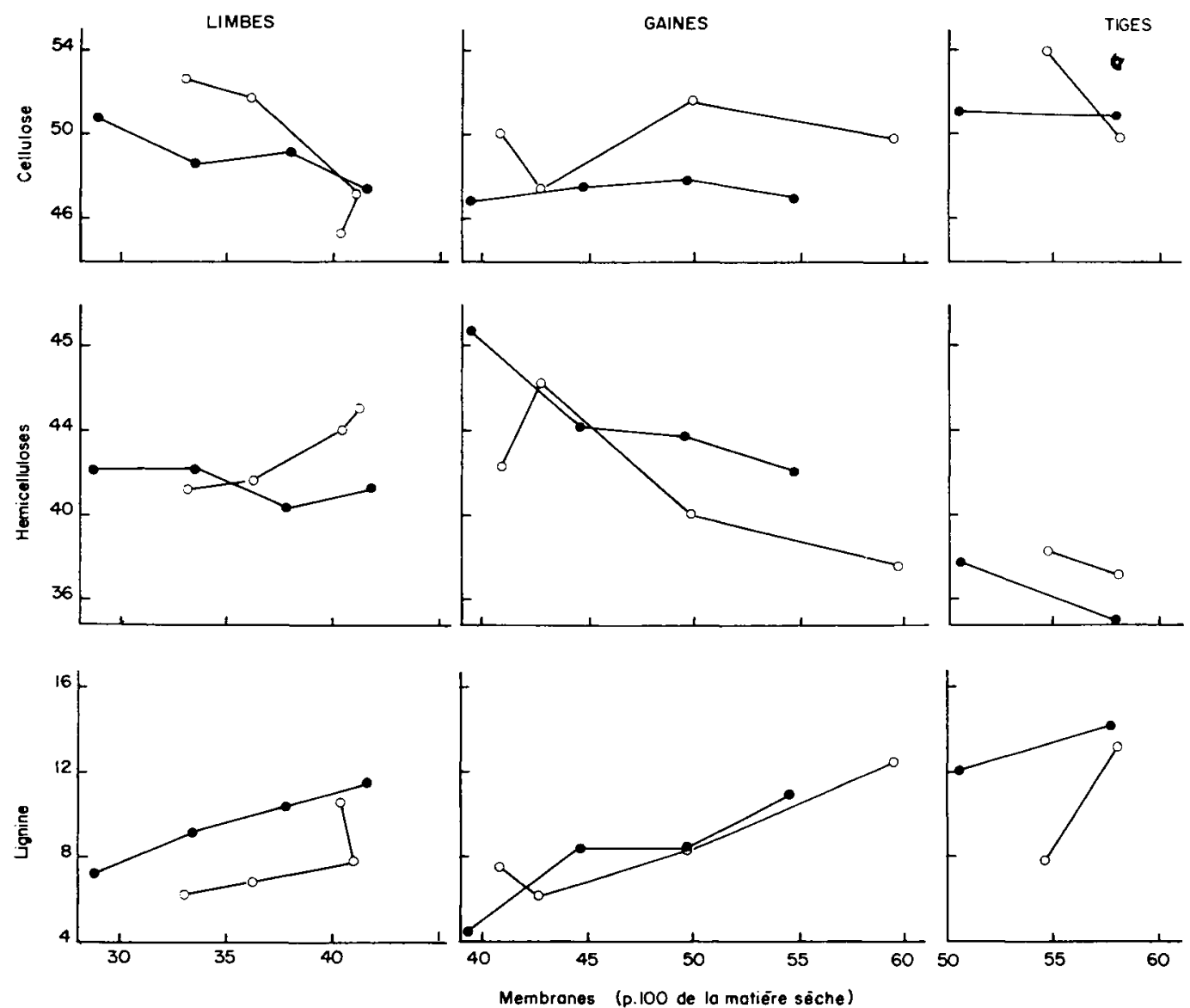

FIG. 2. - Ezolution de la composition des membranes des limbes, gaines et tiges du dactyle et de la fétuque des prés au cours du ${ }^{\mathrm{er}}$ cycle de croissance (en pourcentage des membranes)

dactyle $\bigcirc$ fétuque des prés

Quant aux membranes des feuilles entières (limbes + gaines) de ray-grass anglais, leur composition a présenté une évolution régulière au cours du $\mathrm{I}^{\mathrm{er}}$ cycle, caractérisée par l'augmentation de xylanes et la diminution des hexosanes hydrolysables (tableau r8). Cela doit résulter à la fois des modifications des membranes des limbes et des gaines et de l'accroissement de la proportion des gaines par rapport aux limbes.

Dans les quelques échantillons de tiges étudiés ( 2 de dactyle et 2 de fétuque), la teneur en lignine des membranes a augmenté plutôt au détriment de la teneur en hémicelluloses que la teneur en cellulose.

Reponsses.

Au cours des $2^{\mathrm{e}}, 3^{\mathrm{e}}$ et $4^{\mathrm{e}}$ cycles, la proportion de membranes a augmenté avec l'âge dans les limbes de dactyle $S 26(1)$ mais non pas dans les gaines, tout au moins

(1) Ies échantillons de dactyle $\$ 26$ ont été étudiés par Fauconxead et Guusseres. 
dans la période étudiée correspondant approximativement au deuxième mois de croissance.

Au cours de cette période des différents cycles, les membranes ont conservé une composition relativement constante et leur teneur en lignine n'a augmenté que de façon très limitée (d'environ I unité) ; elles n'ont pas eu la même composition que les membranes des plantes du $\mathbf{I}^{\text {er }}$ cycle, même lorsqu'elles ont représenté le même pourcentage de l'organe (fig. 3). Aussi bien pour les limbes que pour les gaines, elles ont contenu plus de cellulose, moins d'hémicelluloses et, pratiquement, la même quantité de lignine qu'au $\mathrm{I}^{\mathrm{er}}$ cycle (tableau 7 ).
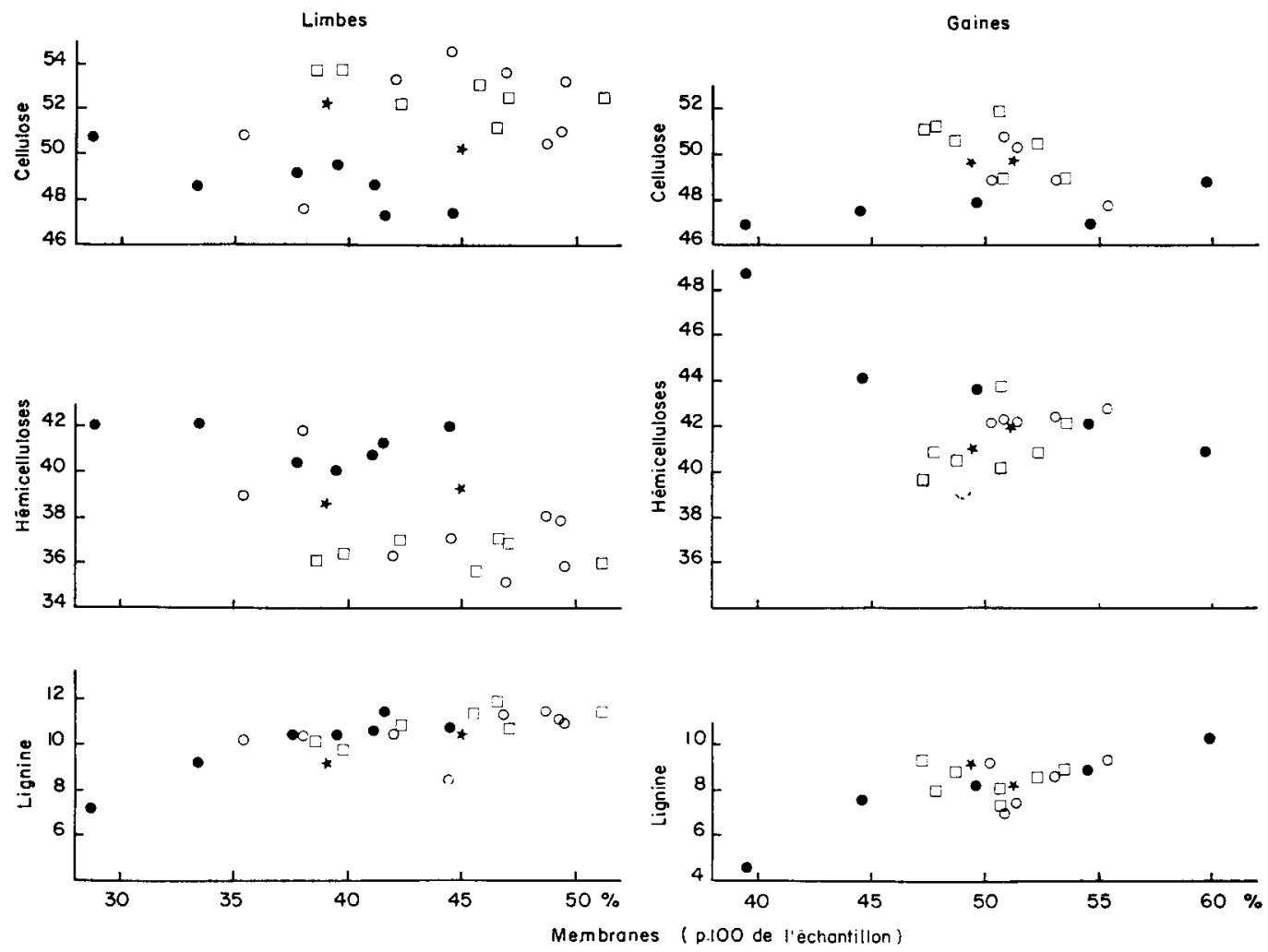

FIG. 3. - Composition des membranes des limbes et des gaines du dactyle au cours des différents cycles de croissance

I ${ }^{\text {er }}$ cycle, (en pourcentage des membranes)

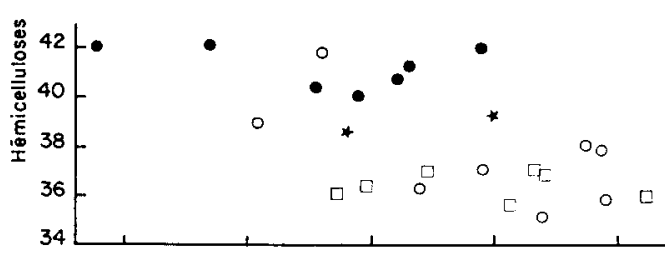

$\mathrm{O}^{\mathrm{e}}$ cycle,

Nous n'avons pas fait d'étude comparable sur les repousses d'autres espèces. Cependant, les données obtenues sur les repousses entières de dactyle $\mathrm{S} 37$ et de ray-grass $\mathrm{S} 24$ coupées tous les mois ou tous les deux mois confirment les précédentes. La figure 4 montre qu'à proportion de limbes égale, les membranes des repousses contiennent généralement moins d'hémicelluloses, plus de cellulose et plus de lignine que celles des plantes du $I^{\text {er }}$ cycle de la même année. Ces variations correspondent à une diminution des xylanes et à une augmentation de la cellulose vraie (tableaux 20 et $2 \mathbf{I}$ ). 


\section{TABLEAU 7}

Influence du cycle de croissance sur la composition moyenne des membranes des limbes et des gaines du dactyle $S 26$

\begin{tabular}{|c|c|c|c|c|c|}
\hline & \multirow{2}{*}{$\begin{array}{c}\text { Nombre } \\
\text { d'échantillons }\end{array}$} & \multirow{2}{*}{$\begin{array}{l}\text { Membranes } \\
(\% \text { de la } \\
\text { matière sèche })\end{array}$} & \multicolumn{3}{|c|}{ en pourcentage des membranes } \\
\hline & & & Hemicelluloses & Cellulose & Lignine \\
\hline \multicolumn{6}{|l|}{ Limbes } \\
\hline 1er cycle.... & 7 & 38,1 & $41,2 \pm 0,75$ & $48,8 \pm 1,20$ & $10,0 \pm 1,38$ \\
\hline $2^{\mathrm{e}}$ cycle $\ldots$. & 8 & 44,3 & $37,7 \pm 2,09$ & $51,8 \pm 2,22$ & $10,5 \pm 0,96$ \\
\hline $3^{e}$ cycle $\ldots$ & 7 & $41^{\prime}, 5$ & $36,4 \pm 0,55$ & $52,7 \pm 0,91$ & $10,9 \pm 0,71$ \\
\hline \multicolumn{6}{|l|}{ Gaines } \\
\hline $1^{\text {er }}$ cycle.... & 5 & 49,6 & $43,9 \pm 2,97$ & $47,6 \pm 0,80$ & $8,5 \pm 2,50$ \\
\hline $2^{\mathrm{e}}$ cycle $\ldots$ & 5 & 52,2 & $42,3 \pm 0,90$ & $49,3 \pm 1,21$ & $8,4 \pm 1,02$ \\
\hline $3^{\text {e }}$ cycle $\ldots$ & 7 & 50,1 & $41,1 \pm 1,43$ & $50,4 \pm 2,78$ & $8,5 \pm 0,69$ \\
\hline
\end{tabular}
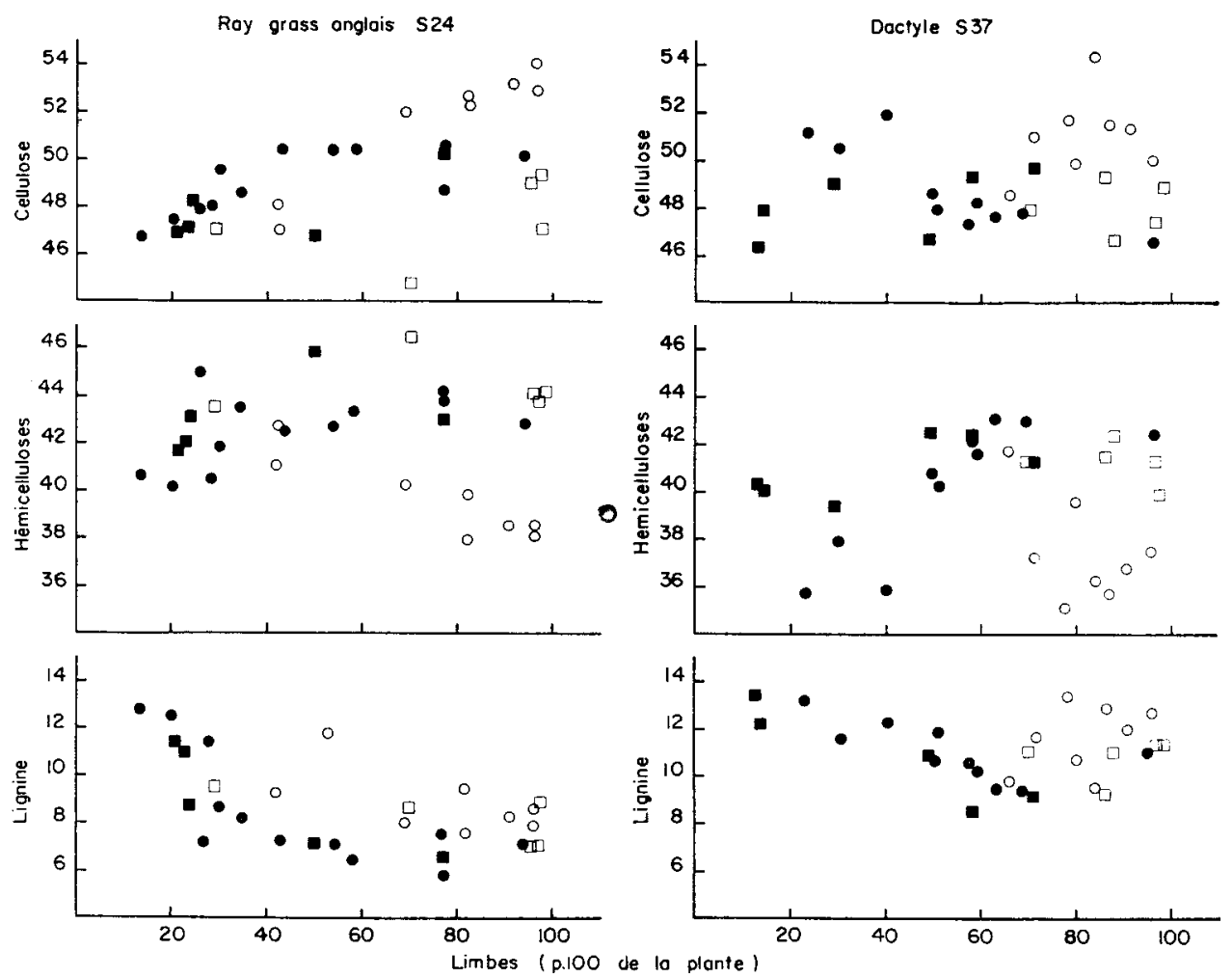

FIG. 4. - Relations entre la composition des membranes du ray-grass anglais $\mathrm{S} 24$ et du dactyle $\mathrm{S} 37$ et la proportion de limbes dans la plante 
Pour les 5 plantes de dactyle prélevées au cours des différents cycles dont on a analysé simultanément les limbes et les gaines, les membranes des limbes ont eu une composition significativement différente $(\mathrm{P}<0,05)$ de celle des gaines : elles ont contenu plus de cellulose et de lignine et moins d'hémicelluloses (tableau 7 ).

\section{Choux}

Les résultats obtenus sur les choux (tableau Ig) ne sont pas exactement comparables à ceux rapportés jusqu'ici puisque les substances pectiques ont été extraites par un traitement par l'oxalate d'ammonium, situé entre le dégraissage et 1'hydrolyse par $\mathrm{SO}_{4} \mathrm{H}_{2} 5$ p. IOO.

Les membranes n'ont représenté qu'une faible proportion de la matière sèche aussi bien dans les limbes (I7,I p. IOO) que dans les tiges (22,0 p. IOO), auxquelles on avait, il est vrai, ajouté les pétioles et les grosses nervures.

Les membranes des limbes ont contenu plus d'arabanes, d'hexosanes hydrolysables et de lignine que celles des tiges, moins de xylanes et, surtout moins de cellulose vraie (45,I au lieu de $52,0 \mathrm{p}$. IOo). Il faut souligner la teneur en cellulose très élevée des tiges et la présence de mannanes en quantité dosable dans les fractions hémicelluloses et cellulose de tous les échantillons. Le fait que les membranes des limbes aient contenu plus de lignine que celles des tiges ( 15,2 au lieu de Io,8 p. roo) surtout pour les choux moelliers, pourrait être dû, au moins en partie, à la présence de produits étrangers dans la lignine des limbes, d'origine cuticulaire par exemple.

\section{PLANTES ENTIÈres}

Nous avons étudié les membranes de 82 échantillons de plantes entières (parties aériennes) prélevées à différents stades de développement, et de 20 foins ; nous avons de plus calculé les teneurs en constituants membranaires de 42 plantes entières à partir de celles de leurs feuilles et de leurs tiges (et de leurs inflorescences), et des proportions de ces différents organes. Nous avons exprimé les résultats de deux façons :

I) en pourcentage de la matière sèche de la plante entière, afin de calculer les relations entre les teneurs des différents constituants et la teneur en membranes (tableaux 8 et 9), et de comparer les espèces fourragères sur cette base (figure 5 à II).

2) en pourcentage des membranes, afin de montrer que la composition des membranes de la plante entière dépend avant tout de la proportion des différents organes.

\section{Graminées}

Nous avons déterminé les teneurs en hémicelluloses, cellulose et lignine de 30 échantillons de ray-grass anglais $\mathrm{S} 24$ et de 32 échantillons de dactyle $\mathrm{S} 37$ récoltés au G. R. I. de Hurley, et de I3 échantillons de ray-grass anglais prélevés au C. N. R. A. de Versailles; elles sont reportées sur les figures 5, 7, 9 et ro parallèlement aux teneurs en membranes. Nous avons séparé les différents polysaccharides de 2 I de ces échantillons de ray-grass anglais et de 8 de ces échantillons de dactyle dont les teneurs sont reportées individuellement dans les tableaux 20 à 22 .

En pourcentage de la plante.

La teneur en membranes de la plante entière a varié dans de très larges limites en fonction de la proportion de tiges et de l'âge; ainsi, au cours du rer cycle de 


\section{TABLEAU 8}

Relations entre les teneurs en constituants membranaires et la teneur en membranes des plantes entières (toutes les teneurs sont en pourcentage de la matière sèche)

\begin{tabular}{|c|c|c|c|c|}
\hline & $\begin{array}{l}\text { Nombre } \\
\text { d'échantillons }\end{array}$ & Hémicelluloses & Cellulose & Lignine \\
\hline \multicolumn{5}{|l|}{ Luserne } \\
\hline Feuilles $\ldots \ldots \ldots \ldots \ldots \ldots$ & 27 & $\begin{array}{l}y=0,32 x+2,06 \\
r=0,61\end{array}$ & $\begin{array}{l}y=0,66 x-0,96 \\
r=0,93\end{array}$ & $\begin{array}{l}y=0,22 x-1,16 \\
r=0,71\end{array}$ \\
\hline Tiges $\ldots \ldots \ldots \ldots \ldots \ldots$ & 27 & $\begin{array}{l}y=0,09 x+9,54 \\
r=0,69\end{array}$ & $\begin{array}{l}y=0,67 x-6,37 \\
r=0,98\end{array}$ & $\begin{array}{l}y=0,24 x-3,17 \\
r=0,88\end{array}$ \\
\hline Plantes entières...$\ldots \ldots$ & 26 & $\begin{array}{l}y=0,1_{4} x+6,57 \\
y=0,87\end{array}$ & $\begin{array}{l}y=0,65 x-5,15 \\
r=0,99\end{array}$ & $\begin{array}{l}y=0,21 x-1,43 \\
r=0,94\end{array}$ \\
\hline Trètle blanc ......... & 9 & $\begin{array}{l}y=0,36 x+0,02 \\
r=0,99\end{array}$ & $\begin{array}{l}y=0,44 x+1,35 \\
r=0,99\end{array}$ & $\begin{array}{l}y=0,20 x-1,37 \\
r=0,96\end{array}$ \\
\hline Ray-grass anglais $S 24$ & & & & \\
\hline 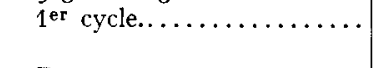 & 17 & $\begin{array}{l}y=0,37 x+2,47 \\
r=0,98\end{array}$ & $\begin{array}{l}y=0,42 x+2,48 \\
r=0,99\end{array}$ & $\begin{array}{l}y=0,21 x-4,96 \\
r=0,93\end{array}$ \\
\hline Repousses $\ldots \ldots \ldots \ldots \ldots$ & 13 & $\begin{array}{l}y=0,33 x+3,23 \\
r=0,74\end{array}$ & $\begin{array}{l}y=0,45 x+1,77 \\
r=0,80\end{array}$ & $\begin{array}{l}y=0,22 x-5,04 \\
r=0,93\end{array}$ \\
\hline Ensemble .............. & 30 & $\begin{array}{l}y=0,37 x+2,02 \\
r=0,93\end{array}$ & $\begin{array}{l}y=0,42 x+2,77 \\
r=0,94\end{array}$ & $\begin{array}{l}y=0,21 x-4,75 \\
r=0,93\end{array}$ \\
\hline Ray-grass anglais "Versailles" & 13 & $\begin{array}{l}y=0,44 x-0,46 \\
r=0,99\end{array}$ & $\begin{array}{l}y=0,38 x+2,58 \\
r=0,98\end{array}$ & $\begin{array}{l}y=0,18 x-2,16 \\
r=0,91\end{array}$ \\
\hline Dactyle $S 37$ & & & & \\
\hline 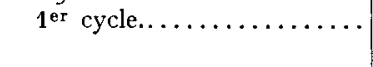 & 19 & $\begin{array}{l}y=0,30 x+4,60 \\
r=0,95\end{array}$ & $\begin{array}{l}y=0,52 x-1,42 \\
r=0,98\end{array}$ & $\begin{array}{l}y=0,18 x-3,13 \\
r=0,97\end{array}$ \\
\hline Repousses ............. & 13 & $\begin{array}{l}y=0,28 x+4,37 \\
r=0,80\end{array}$ & $\begin{array}{l}y=0,56 x-2,61 \\
r=0,96\end{array}$ & $\begin{array}{l}y=0,16 x-1,76 \\
r=0,82\end{array}$ \\
\hline Ensemble $\ldots \ldots \ldots \ldots \ldots$ & 32 & $\begin{array}{l}y=0,32 x+3,18 \\
r=0,92\end{array}$ & $\begin{array}{l}y=0,51 x-0,79 \\
r=0,98\end{array}$ & $\begin{array}{l}t=0,17 x-2,39 \\
r=0,93\end{array}$ \\
\hline Graminérs à floraison........ & 8 & $\begin{array}{l}y=0,42 x-2,08 \\
r=0,86\end{array}$ & $\begin{array}{l}y=0,47 x+1,27 \\
r=0,90\end{array}$ & $\begin{array}{l}y=0,11 x+0,81 \\
r=0,56\end{array}$ \\
\hline Foins de pré.. & 20 & $\begin{array}{l}y=0,27 x+4,60 \\
r=0,75\end{array}$ & $\begin{array}{l}y=0,60 x-6,24 \\
r=0,90\end{array}$ & $\begin{array}{l}y=0,13 x+1,55 \\
r=0,55\end{array}$ \\
\hline
\end{tabular}

\section{TABI,EAU 9}

Relations entre les teneurs en xylanes totaux et en cellulose vraie et la teneur en membranes des plantes entières (toutes les teneurs sont en pourcentage de la matière sèche)

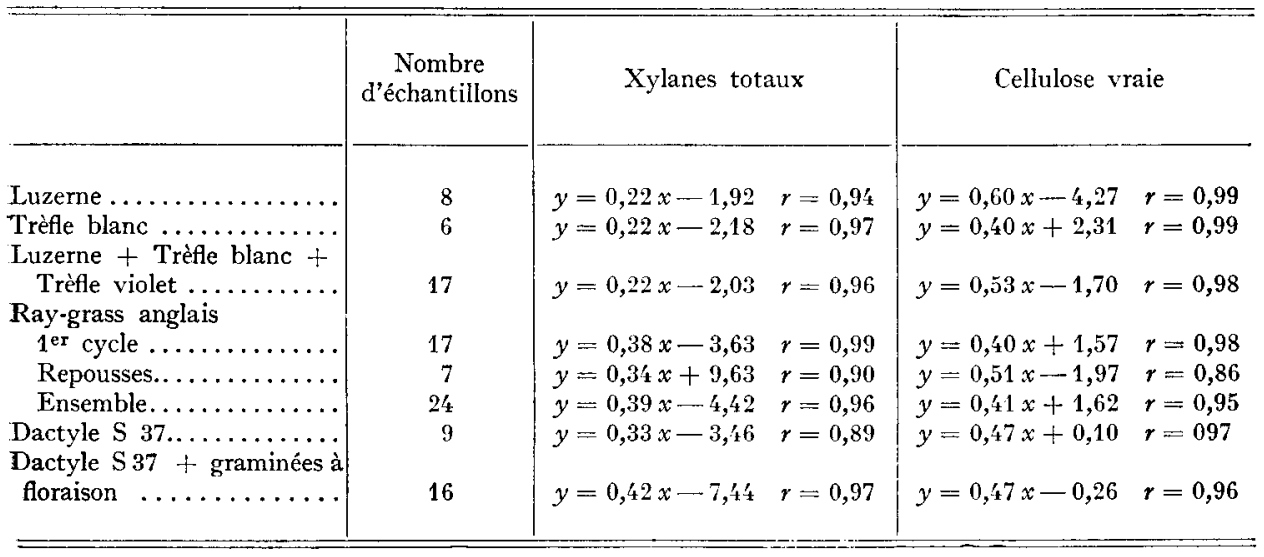



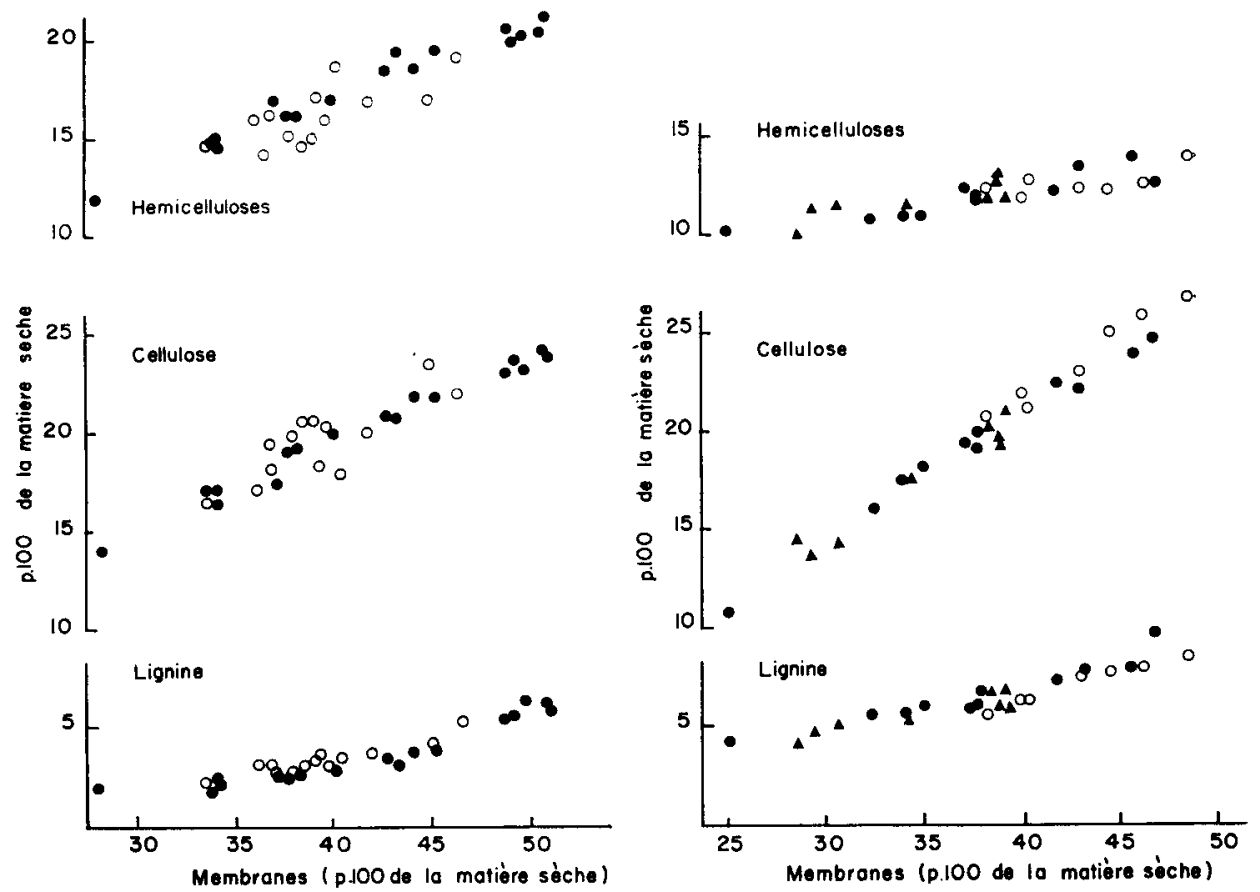

Fig. 5. - Relations entre les teneurs en hémicelluoses, cellulose et lignine, et la teneur en membranes des plantes entières de ray-grass anglais $\mathrm{S}_{2} 4$ - er cycle

$\bigcirc$ repousses

FIG. 6. - Relations cntre les teneurs en cellulose et lignine, et la teneur en membranes des plantes entières de luzerne I er cycle $\Delta 2^{\mathrm{e}}$ cycle $\square 3^{\mathrm{e}}$ ou $4^{\mathrm{e}}$ cycle
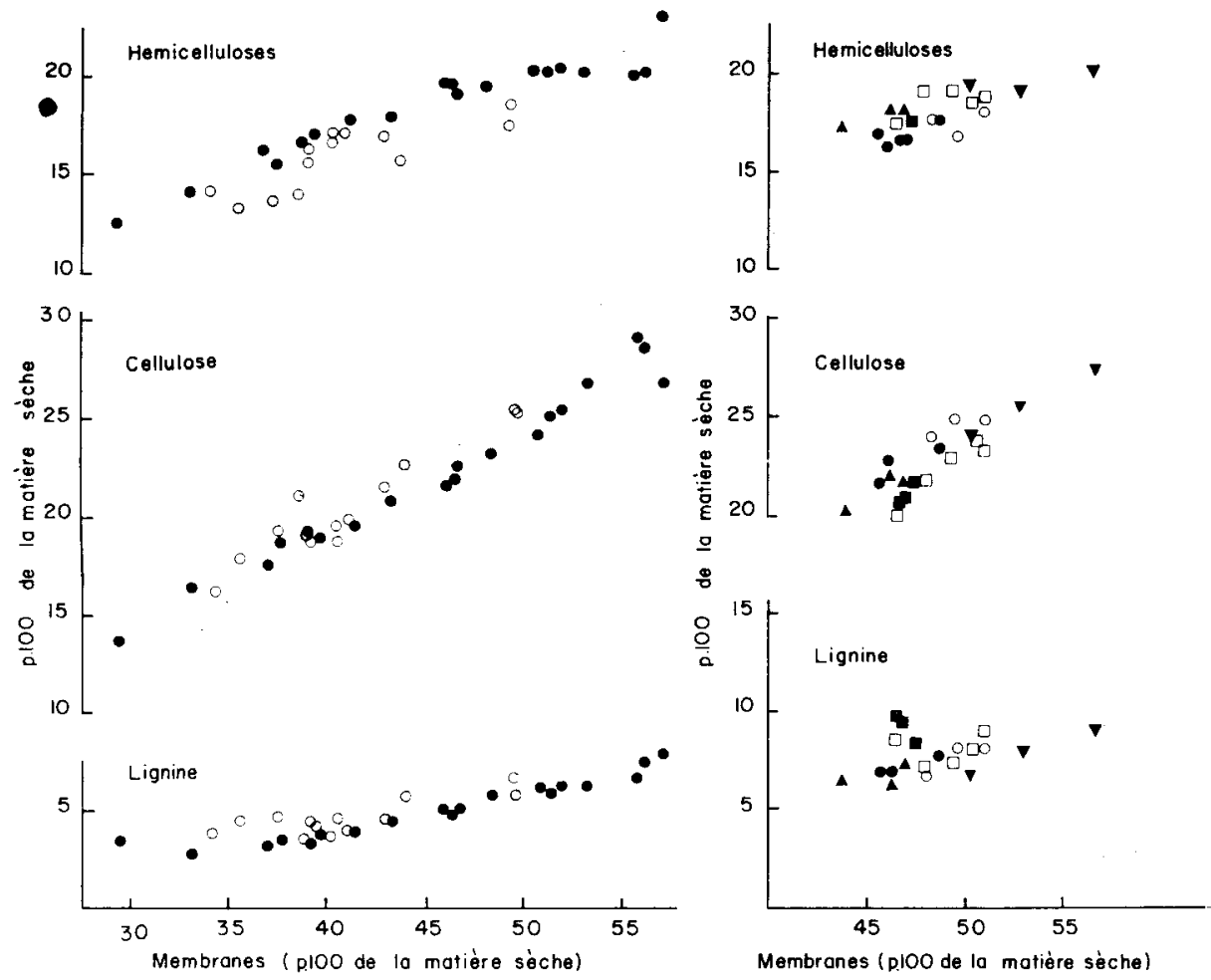

FIG. 7. - Relations entre les teneurs en hémicelluloses, cellulose et lignine, et la teneur en membranes des plantes entieres de dactyle $\$ 37$

- ier cycle Orepousses

Membranes (p.100 de la matière sèche)

FIG. 8. - Relations entre les teneurs ery hémicelluloses, cellulose et lignine, et la teneur en membranes des toins de prairies d'altitude 
¿rorssance elle a varié de moins de 30 p. Ioo à plus de $5^{\circ} \mathrm{p}$. Ioo chez le ray-grass anglais (figure 5).

Pour les deux espèces, l'augmentation de la teneur de la plante en membranes avec l'âge ou la proportion de tiges, indépendamment du cycle de croissance, résulte presque exclusivement d'une augmentation des teneurs en cellulose vraie, en xylanes et en lignine ; en revanche, les teneurs en arabanes et hexosanes hydrolysables ne présentent pas d'évolution très nette et peuvent être considérées comme grossièrement constantes : respectivement 2,88 p. IOO $\pm 0,53$ et 3,64 p. IOO $\pm 0,67$ pour le ray-grass anglais (fig. 9) ; 2,78 p. I00 $\pm 0,44$ et 4,32 p. IOO $\pm 1,23$ pour le dactyle (fig. Io). C'est pourquoi la teneur en hémicelluloses augmente moins vite que la teneur en cellulose lorsque la teneur en membranes augmente : les coefficients de régression (tableau 8 ) sont respectivement de 0,37 et 0,42 pour le ray-grass anglais S 24 (fig. 9), de 0,32 et 0,5 I pour le dactyle (figure ro).

En pourcentage des membranes.

Au cours du premier cycle de croissance, la composition des membranes a subi une évolution caractéristique en même temps que la proportion des membranes dans la plante augmentait, et que la proportion des limbes diminuait (fig. 4).

La teneur des membranes en arabanes et hexosanes hydrolysables a diminué ; la teneur en xylanes a augmenté constamment, de façon plus limitée cependant chez le dactyle que chez le ray-grass où elle a présenté des valeurs de $25 \mathrm{p}$. roo environ au stade feuillu et 30-32 p. Ioo à la floraison dans les 3 souches étudiées. La teneur des membranes en cellulose a eu généralement tendance à diminuer sauf chez le dactyle S 37 en I958. Leur teneur en lignine a augmenté au cours du premier cycle, passant de 8-9 p. IOo à I3-I4 p. Ioo chez le dactyle S 37 et de 6-7 p. IOO à I2-I3 p. Ioo chez le ray-grass $\mathrm{S} 24$; chez ce dernier elle a augmenté beaucoup plus rapidement après l'épiaison qu'auparavant.

TABLEAU IO

Comparaison entre la composition moyenne des membranes du ray-grass anglais $S 24$ et du dactyle $S 37$

\begin{tabular}{|c|c|c|c|c|}
\hline & \multicolumn{2}{|c|}{ Ray-grass anglais S 24 } & \multicolumn{2}{|c|}{ Dactyle S 27} \\
\hline & $1^{\text {er }}$ cycle & Repousses & $1^{\mathrm{er}} \mathrm{cucl}$ s & Repousses \\
\hline Nombre d'échantillons ............. & 17 & 13 & 19 & 13 \\
\hline Membranes ( $\%$ de la plante)...$\ldots \ldots$ & 41,7 & 39,4 & 45,5 & 40,9 \\
\hline \multicolumn{5}{|l|}{ Composition des membranes $(\%)$} \\
\hline Hemicelluloses $\ldots \ldots \ldots \ldots \ldots \ldots \ldots$ & 42,7 & 41,5 & 40,7 & 38,9 \\
\hline Cellulose $\ldots \ldots \ldots \ldots \ldots \ldots \ldots$ & 48,7 & 49,9 & 48,5 & 49,8 \\
\hline Lignine $\ldots \ldots \ldots \ldots \ldots \ldots \ldots \ldots$ & 8,6 & 8,6 & 10,8 & 11,3 \\
\hline Nombre d'échantillons ............. & 4 & $\dot{t}$ & 4 & 4 \\
\hline Membranes (\% de la plante)......... & 44,2 & 42,0 & 45,2 & 46,5 \\
\hline Composition des membranes (\%) & & & & \\
\hline \multicolumn{5}{|l|}{ Hémicellusoses } \\
\hline 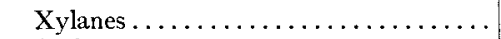 & 26,0 & $\geq 1,4$ & 23,7 & 21,1 \\
\hline Arabanes..$\ldots \ldots \ldots \ldots \ldots \ldots \ldots \ldots \ldots$ & 7,1 & 7,3 & 6,9 & 5,4 \\
\hline Hexosanes hydrolysables ........... & 8,9 & 10,8 & 9,4 & 10,4 \\
\hline \multicolumn{5}{|l|}{ Cellulose } \\
\hline 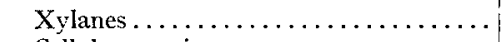 & 3,0 & 2,3 & 3,0 & 2,8 \\
\hline Céllulose vraie...$\ldots \ldots \ldots \ldots \ldots \ldots$ & 45,1 & 48,8 & 46,3 & 48,2 \\
\hline
\end{tabular}



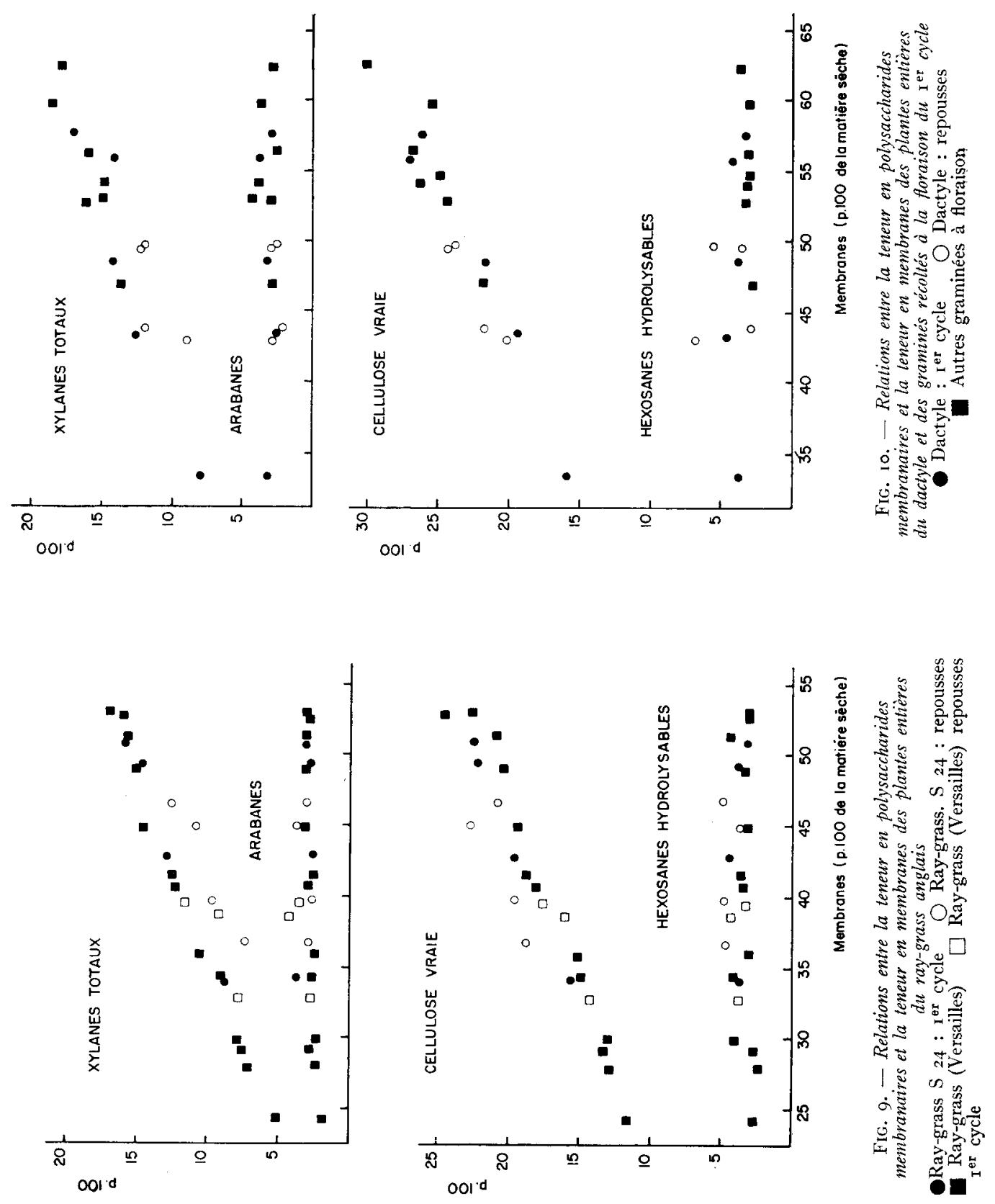
Ces variations de la composition des membranes de la plante entière au cours du premier cycle, résultent avant tout des modifications de la composition anatomique de la plante, et, à un degré beaucoup plus faible, du vieillissement de chacun des organes. Elles sont en excellent accord avec celles que nous avons obtenues sur les membranes des limbes, des gaines, des tiges et des inflorescences à partir desquelles elles auraient presque pu être calculées.

La proportion de limbes est également le facteur prépondérant de la teneur en constituants membranaires des repousses, mais il a déjà été montré, qu'à proportion de limbes égale, les membranes des repousses contenaient sensiblement plus de celluloses et de lignine et moins de xylanes et d'hémicelluloses, que celles du premier cycle (tableau 7 - fig. 4). De même, à teneur en membranes égale, les repousses contiennent plus de cellulose et de lignine et moins d'hémicelluloses (fig. 5 et 7 ) plus de cellulose vraie et d'hexosanes hydrolysables et moins de xylanes (fig. 9 et ro).

\section{Différence entre le ray-grass anglais et le dactyle.}

Nous avons disposé d'un nombre suffisant d'échantillons de ray-grass $\mathrm{S} 24$ et de dactyle $\mathrm{S} 37$ qui ont été cultivés dans le même milieu et récoltés à stade ou âge comparable, pour faire une comparaison valable entre les membranes de ces deux plantes.

A âge égal, le ray-grass S 24 contient moins de constituants membranaires que le dactyle $\mathrm{S} 37$, et a des membranes qui sont plus riches en hémicelluloses et moins lignifiées que celles du dactyle (tableau Io). Ces deux dernières différences sont hautement significatives $(\mathrm{P}<0, \mathrm{OOI})$ à la fois pour les plantes du premier cycle ( $\mathrm{I} 7$ couples de valeurs) que pour celles des repousses ( 13 couples de valeurs). Elles ne sont pas dues à des différences dans la composition morphologique puisqu'elles apparaissent également lorsqu'on compare les deux plantes à proportion de limbes égale (fig. 4), ou à teneurs en membranes égale (figures 5 et 7 ). Quand celle-ci augmente, la teneur en cellulose augmente plus rapidement chez le dactyle que chez le ray-grass (tableau 8 ) mais la teneur en hémicelluloses augmente plus rapidement chez le ray-grass que chez le dactyle.

La différence dans la teneur en hémicelluloses résulte presque exclusivement d'une différence dans la teneur en xylanes, les membranes du ray-grass (tableau 20) contenant systématiquement plus de xylanes que celles du dactyle (tableau $2 \mathrm{I}$ ). Il n'est pas impossible que cela soit d $\hat{u}$, au moins en partie, au fait que les xylanes du dactyle pourraient subir une certaine destruction au cours de l'hydrolyse par $\mathrm{SO}_{4} \mathrm{H}_{2} 5$ p. IOO (JARRIGE - I96I).

\section{Légumineuses}

A partir de la composition des feuilles et des tiges et des proportions respectives de celles-ci, nous avons calculé la teneur en constituants membranaires des plantes entières en admettant que celles-ci ne contenaient que des feuilles et des tiges. L'erreur ainsi commise est relativement faible puisque les inflorescences n'ont représenté qu'une proportion faible des luzernes étudiées: de o à $\mathrm{I}, 6 \mathrm{p}$. Ioo avec une moyenne de 3,o p. Ioo. Ces calculs ont été effectués pour les fractions hémicelluloses, cellulose et lignine de 26 des 27 luzernes étudiées, et pour les différents polysaccharides de 8 d'entre elles (tableau II) (la composition anatomique de l'échantillon $n^{0} 5$, tableau II, n'avait malheureusement pas été notée), de même que pour les trois 
trèfles violets (tableau I2). Les teneurs sont présentées en fonction de la teneur en membranes dans les figures 6 et II.

La teneur en membranes de la luzerne a varié en gros de 25 à $50 \mathrm{p}$. IOo, en fonction de la proportion de tiges et du stade de développement. L'augmentation de la teneur en cellulose rend compte de près des deux tiers $(b=0,65-$ tableau 8$)$ de l'augmentation de la teneur en membranes de la plante entière au cours des différents
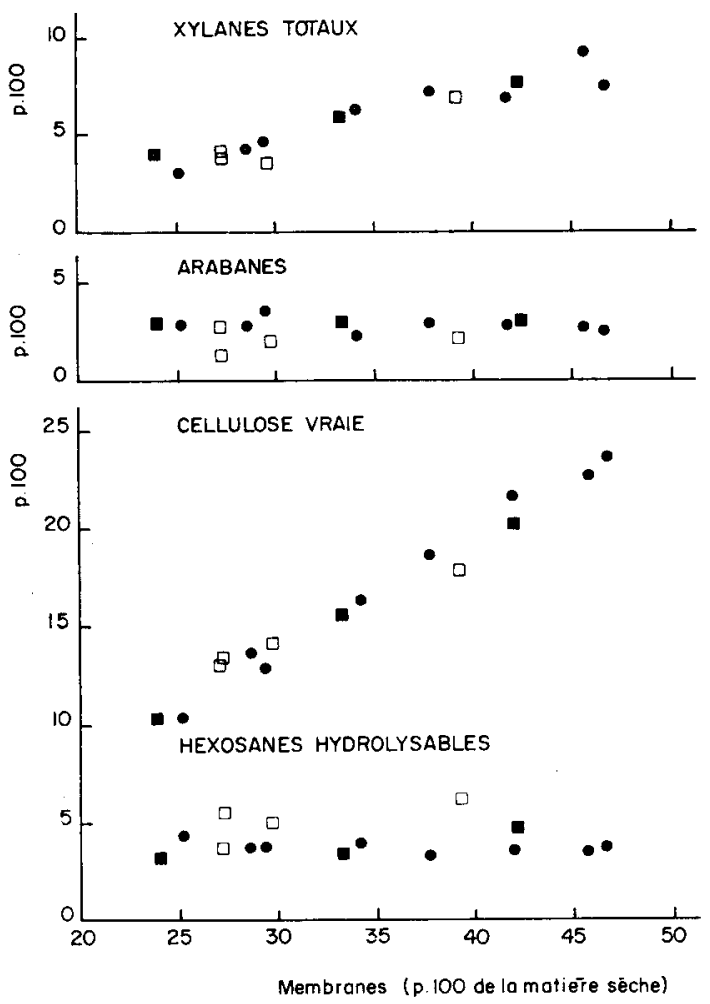

FIG. Ir. - Relations entre la teneur en polysaccharides membranaires et la teneur en membranes des plantes entieres des légumineuses
- Luzerne
Trèfle violet
$\square$ Trèfle blanc

cycles de croissance. En revanche, la teneur en hémicelluloses n'augmente que très lentement $\left(b=0, I_{4}\right)$ : pratiquement elle passe de Io à I4 p. Ioo seulement lorsque la teneur en membranes varie de 25 à 50 p. Ioo (fig. 6); cela traduit le fait que la teneur en xylanes $(b=0,22)$ augmente lentement alors que les teneurs en arabanes et en hexosanes hydrolysables ont tendance à diminuer (fig. II) mais de façon très faible, de telle sorte qu'on peut les considérer comme constantes : 2,75 p. Ioo $+0,40$ et 3,75 p. Ioo $\pm 0,34$ de la plante, respectivement. La teneur en lignine augmente avec la teneur en membranes de façon très régulière et comparable pour les différents cycles de croissance.

Corrélativement, la composition des membranes de la plante entière subit une 
évolution au cours des différents cycles de croissance ; leur teneur en lignine et, surtout, leur teneur en cellulose augmentent au détriment des teneurs en hémicelluloses, en arabanes et en hexosanes hydrolysables.

A proportion de membranes égale dans la plante entière, les teneurs en constituants membranaires des trois trèfles violets ont été voisines de celles de la luzerne (fig. 6 et I I). Il en a été de même pour les teneurs en xylanes et en lignine du trèfle blanc; en revanche, la teneur en cellulose a augmenté plus lentement chez le trèfle blanc que chez la luzerne.

\section{Foins de pré}

Nous avons déterminé les teneurs en hémicelluloses, cellulose et lignine (fig. 8) de 20 foins récoltées dans Io prairies à flore complexe, situées entre 900 et I 000 mètres d'altitude, dans les départements du Cantal, du Puy-de-Dôme, de la HauteSavoie et des Hautes-Alpes. Leur teneur en membranes a varié dans des limites relativement étroites, de 43,9 à $56,7 \mathrm{p}$. Ioo avec une moyenne de $56,7 \mathrm{p}$. Ioo.

C'est la teneur en cellulose qui a présenté la liaison la plus étroite avec la teneur en membranes $(r=0,90)$, et qui a rendu compte de la majeure partie des variations de celle-ci $(b=0,60)$ Quand la teneur en membranes a augmenté (tableau 8), la teneur en hémicelluloses a augmenté $(b=0,27)$ mais la teneur en lignine n'a pas augmenté de façon significative.

Les membranes de ces foins ont contenu en moyenne 36,9 p. Ioo \pm I,58 d'hémicelluloses, 46,9 p. I00 $\pm I, 96$ de cellulose et 16,2 p. Ioo $\pm 2,02$ de lignine. Ces variations sont relativement limitées pour les hémicelluloses et la cellulose, et beaucoup plus importantes pour la lignine. Elles doivent être dues en majeure partie aux variations de la composition botanique ; en effet, sur 5 des ro prairies, on a récolté des foins à trois stades de croissance du premier cycle, et on a alors constaté des différences systématiques entre foins de prairies différentes. Quand la proportion des membranes a augmenté, leur teneur en hémicelluloses a eu tendance à diminuer, surtout au bénéfice de la teneur en cellulose.

\section{DISCUSSION}

L'examen de 1'ensemble des résultats obtenus permet:

a) d'analyser l'importance relative des différents facteurs de variation des teneurs en constituants membranaires de la plante entière,

b) de montrer qu'il existe dans la composition des membranes, des différences importantes entre espèces de familles différentes,

c) de dégager certaines lois générales de la composition des membranes.

Avant d'exposer ces différents aspects, il est cependant nécessaire de rappeler les limites des méthodes d'analyse et d'interprétation qui ont été utilisées (cf. JARRIGE rg60).

\section{CRITIQUE DES MÉTHODES UTILISÉES}

Nous avons séparé l'ensemble des polyoses de la membrane en deux groupes appelés " hémicelluloses " et " cellulose ". 
I. Ces termes sont employés dans des buts tellement différents suivant les auteurs, qu'ils doivent d'abord être bien précisés. Le terme de cellulose est parfaitement justifié puisque la fraction qu'il désigne contient en moyenne $95 \mathrm{p}$. Ioo de cellulose vraie (glucosane) et une proportion faible et relativement constante de xylanes résiduels (de 1'ordre de $4 \mathrm{p}$. Ioo dans les légumineuses et de 5-6 p. Ioo dans les graminées (tableau 5) et présente très rarement de l'arabinose. Elle contient plutôt moins de polysacharides non cellulosiques que $1^{\prime} \alpha$-cellulose de référence obtenue après les traitements alcalins (résultats non publiés).

Sous le terme d'hémicelluloses nous avons désigné tous les polyoses hỹdrolysés par $\mathrm{SO}_{4} \mathrm{H}_{2}$ à $5 \mathrm{p}$. Ioo pendant 3 heures, provenant à la fois des hémicelluloses et des substances pectiques. Le terme de polyoses membranaires non cellulosiques correspondrait mieux à cet ensemble et prêterait moins à confusion que le terme d'hémicelluloses que nous avons choisi, mais il serait beaucoup plus lourd à employer. Nous n'avons pas déterminé séparément les hémicelluloses et les substances pectiques en extrayant celles-ci au préalable (par l'oxalate d'ammonium par exemple) pour les raisons suivantes : $\mathrm{I}^{\circ}$ ) cette séparation est relativement conventionnelle ; $2^{\circ}$ ) les teneurs en substances pectiques des graminées sont faibles, en général inférieures à 2 p. Ioo de la matière sèche (Buston, I934; Phillips et al., r942 ; Ferguson, I948; WAITE et GORROD, I959) ; $3^{\circ}$ ) les substances pectiques sont composées en majeure partie d'acides uroniques que nous n'avons pas dosés, et donnent à l'hydrolyse les mêmes sucres que les hémicelluloses mais en proportions différentes : 1'arabinose est plus important, le glucose et surtout le xylose sont en proportions plus faibles.

Ces sucres ne représentent finalement qu'une faible proportion de la matière sèche, même dans les légumineuses qui sont riches en substances pectiques. Nous les avons estimés par différence entre les résultats obtenus sans extraction des subtances pectiques par l'oxalate d'ammonium (WEIHE et PHILLIPS, I947) et ceux obtenus après cette extraction (JARRIGE, I96I). Nous avons ainsi constaté que la fraction polyose des substances pectiques ne représentait qu'environ $3 \mathrm{p}$. Ioo de la matière séche des feuilles et des tiges de luzerne (et de 0,6 à 0,8 p. Ioo de celle des betteraves) ; elle représente en moyenne $22 \mathrm{p}$. Ioo et $\mathrm{I} 3 \mathrm{p}$. Ioo de la fraction hémicelluloses obtenue sans extraction préalable respectivement pour les feuilles et pour les tiges de luzerne et ${ }_{5} 5$ et $5 \mathrm{p}$. Ioo de la somme hémicelluloses + cellulose.

2. La séparation qui a été réalisée par les hydrolyses acides entre les deux fractions hémicelluloses et cellulose n'est pas absolue. Elle est très satisfaisante pour certains polysaccharides puisque 1 'hydrolyse par $\mathrm{SO}_{4} \mathrm{H}_{2}$ à 5 . p roo pendant 3 heures a permis d'extraire la totalité des arabanes et des galactanes dans presque tous les échantillons et de 85 à 90 p. Ioo des xylanes (tableau 5). Elle est plus incertaine en ce qui concerne les glucosanes : la proportion des hexosanes totaux qui a été hydrolysée par $\mathrm{SO}_{4} \mathrm{H}_{2}$ à 5 p. Ioo a présenté des différences importantes avec la nature des échantillons (tableau 5 ) : elle a varié en gros de ro p. Ioo pour les gaines et les tiges de graminées à un peu plus de $30 \mathrm{p}$. Ioo pour les feuilles de luzerne.

Il n'est pas possible de savoir si le glucose, qui est l'hexose principal de l'hydrolysat 5 p. Ioo, provient exclusivement de polysaccharides non cellulosiques ou, dans une proportion appréciable et variable avec l'origine des échantillons, de l'attaque de la cellulose elle-même. La frontière entre les hémicelluloses et la cellulose des plantes fourragères est trop mal connue et trop conventionnelle pour qu'on puisse 
actuellement lever cette incertitude que notre méthode partage d'ailleurs avec les autres méthodes de fractionnement des membranes (cf. JARRIGE, I96I).

3. Le fait que nous n'ayons pas dosé les acides uroniques nous conduit à sousestimer les membranes dans des proportions variables avec la catégorie d'échantillons. Les données dont on dispose actuellement sur la teneur en acides uroniques des plantes fourragères sont en nombre extrêmement limité et ne sont pas aisément comparables parce qu'elles ont été obtenues et, même, exprimées de façon différente.

Les léguminetuses en sont relativement riches, probablement à cause de leur teneur élevée en substances pectiques : I0,5 à I2,2 p. IOO (de la matière sèche) d'acides uroniques totaux dans les feuilles de luzerne et 6,6 à 9,8 p. Ioo dans les tiges correspondantes (HIrsi et al., I959) ; 9,8 à Io,8 p. Ioo d'uronides dans les 4 échantillons de trèfle violet étudiés par SALO (I96I). Les graminées présentent des teneurs nettement plus faibles : 4,8 à 7,0 p. Ioo d'anhydride uronique dans la fléole (PhILLIPs et al., I942); 2,0 à 3,2 p. Ioo d'anhydride uronique dans les feuilles, 2,0 à 3,6 p. roo dans les tiges et 2,4 à 3,3 p. Ioo dans les inflorescences des cing espèces analysées par WAITE et GorRoD (I959), soit dans les trois cas 6 à $7 \mathrm{p}$. IOO des polysaccharides autres que les acides uroniques; 3,5 à 4,3 p. Ioo d'uronides dans trois échantillons de graminées (SALO, I96I).

Les teneurs correspondantes en polysaccharides membranaires et en lignine ayant été rapportées pour ces différents échantillons, il est possible de calculer la teneur en anhydride uronique en pourcentage des membranes telles que nous les avons définies; on obtient ainsi des valeurs moyennes de l'ordre de $15 \mathrm{p}$. roo et de $35 \mathrm{p}$. Ioo respectivement pour les tiges et les feuilles de légumineuses, et de $5 \mathrm{p}$. roo pour les graminées après épiaison (peut-être jusqu'à Io p. Ioo dans les graminées feuillues) ; il faudrait donc augmenter d'autant les membranes que nous avons calculées d'après nos résultats pour avoir une estimation plus exacte des membranes réelles. Cette erreur par défaut dans l'estimation des membranes a entraîné une erreur par excès dans les teneurs des constituants exprimées en pourcentage des membranes; cette dernière erreur est faible pour les graminées et même pour les tiges de légumineuses, mais importante pour les feuilles de légumineuses ; il faut en tenir compte lorsque nous comparons la composition des membranes des feuilles de légumineuses à celle de membranes des autres échantillons.

4. La méthode de dosage des trois fractions membranaires et des polysaccharides isolés que nous avons utilisée est elle-même sujette à certaines causes d'imprécisions ou d'erreurs. En premier lieu l'estimation des deux fractions hémicelluloses et cellulose par le pouvoir réducteur de leurs hydrolysats peut être faussée : par excès d'une part, lorsque 1'hydrolysat contient d'autres constituants réducteurs, par défaut d'autre part, lorsque 1'hydrolyse est incomplète ou que certains sucres sont partiellement détruits, comme ce peut être cas pour le xylose dans certains échantillons (cf. JARRIGE, I96r). En second lieu, l'hypothèse suivant laquelle les différents sucres subissent des pertes relatives égales au cours des différentes opérations allant de la neutralisation de l'hydrolysat au dosage après séparation chromatographique, peut ne pas être vérifiée pour tous les échantillons étudiés. Enfin, le fait de ne pas doser les sucres révélés à l'état de trace et les produits d'hydrolyse incomplète lorsqu'ils sont présents a conduit à une estimation légèrement par excès des sucres principaux dans certains échantillons.

Ce sont là des causes d'incertitude, d'imprécision ou d'erreur dont il faut tenir 
compte mais qui sont difficiles à éliminer et dont certaines doivent affecter, à des degrés divers, toutes les autres méthodes de fractionnement des membranes. En revanche, la méthode utilisée présente l'avantage d'avoir été effectivement mise au point en vue d'analyser les membranes des plantes fourragères et d'être relativement rapide, ce qui a permis d'étudier un plus grand nombre d'échantillons. Enfin elle a fourni des résultats tout à fait comparables à ceux obtenus par les autres auteurs.

\section{LES MEMBRANES DE LA PLANTE ENTIÈRE}

La teneur de la plante entière en constituants membranaires augmente avec l'âge au cours de chacun des cycles de croissance, cette augmentation étant la plus ample au cours du I ${ }^{\text {er }}$ cycle : à la floraison, la teneur en cellulose est ainsi approximativement deux fois plus élevée qu'au début de la croissance, et la teneur en lignine trois fois plus élevée. Il est bien connu que la composition anatomique de la plante est le facteur, de loin le plus important, de ces variations, et que les tiges contiennent plus de membranes que les limbes foliaires. Les données que nous avons obtenues sur les constituants membranaires des différents organes aux principaux stades decroissance, confirment d'abord ce fait ; elles permettent ensuite de mesurer l'importance des autres facteurs, notamment celles de l'âge et du cycle sur la teneur et la composition des membranes de chaque organe. Elles montrent enfin, que les teneurs des différents constituants membranaires ne varient pas exactement dans les mêmes proportions, et que la composition moyenne des membranes de la plante entière ne demeure donc pas constante.

\section{Différences entre organes}

Entre les feuilles ou les limbes, et les tiges de toutes les espèces étudiées, existent des différences de même nature dans la composition des membranes. Les membranes des limbes foliaires contiennent plus d'hémicelluloses, d'arabanes et d'hexosanes hydrolysables que celles des tiges, et moins de cellulose vraie et de xylanes (le trèfle violet faisant exception à ce dernier point de vue) ; cela confirme les observations antérieures (tableau I) effectuées sur les graminées (WAITE et GorRoD I959 MackenziE et Wylam I959), et sur la luzerne (Hirs't et al., r950). Ces différences sont beaucoup plus limitées chez les graminées que chez les légumineuses où elles s'accroissent avec l'âge, pour des causes qui seront examinées plus loin.

Les membranes des tiges sont généralement plus riches en lignine corrigée que celles des feuilles, mais les différences ne sont pas toujours significatives et demeurent limitées et beaucoup plus faibles que celles qu'on aurait pu attendre, d'après les différences observées dans la structure et de rôle des deux organes. Cette divergence résulte déjà en partie du fait que nous avons surestimé la teneur en lignine des membranes, de façon plus importante dans les feuilles que dans les tiges, en ne tenant pas compte des acides uroniques dans l'estimation des membranes ; l'erreur ainsi commise n'est cependant importante que pour les légumineuses, et explique dans une certaine mesure la teneur en lignine apparemment élevée des membranes de leurs feuilles. I1 est ensuite possible que la lignine isolée des feuilles contienne plus d'impuretés non azotées, que celle isolée des tiges; enfin, il faudrait peut-être appliquer un facteur 
de transformation plus élevé pour les feuilles que pour les tiges, à l'azote de la lignine brute, pour estimer la lignine corrigée ('TIL $\mathrm{L}_{\mathrm{EY}}$, communication personnelle). Ce sont là des hypothèses qui ne pourront être vérifiées que lorsqu'on connaîtra beaucoup mieux les caractéristiques des lignines des plantes fourragères (cf. Journet et JARRIGE I962).

L,es membranes des gaines de graminées ont une composition intermédiaire entre celles des limbes et des tiges, plus voisine cependant de celle des limbes. Les membranes des inflorescences de graminées ont une composition spécifique caractérisée par une très forte teneur en xylanes et une faible teneur en cellulose ; ce fait déjà observé par WAITE et GoRRoD (I959), pourrait expliquer en partie pourquoi la teneur de la plante entière en cellulose vraie ou en cellulose brute WEENDE augmente relativement peu à la fin du $I^{\text {er }}$ cycle ; les inflorescences représentent en effét près de 20 p. roo de la matière sèche des graminées à la floraison (tableau I 7).

\section{Stade de croissance et lignification}

D'après l'évolution avec 1'âge de la proportion et de la composition des membranes, on peut répartir en trois catégories les échantillons d'organes étudiés.

a) Dans les feuilles de légumineuses, la proportion et la composition des membranes ne présentent pas d'évolution importante avec l'âge, et demeurent relativement constantes, tout au moins pendant la période où on exploite ces plantes. Il en est de même pour les feuilles et les tiges de choux, pendant la période de deux à trois mois à la fin de l'automne et au début de l'hiver, où on les récolte traditionnellement. Il n'en demeure pas moins possible que les membranes de ces divers organes aient une composition sensiblement différente, d'une part au début de la croissance, et d'autre part avec le dépérissement qui suit la floraison : c'est ce que suggèrent les résultats de Hinst et al. (I960), sur les feuilles de luzerne prélevées après la formation des graines.

Nos résultats expliquent la teneur en cellulose brute relativement constante avec l'âge, observée antérieurement sur les feuilles de luzerne (WoOdman et Evans r935), de trèfle violet (WILSIE et HOLLOWEL, I948), et de sainfoin (BAKER et al., I952).

b) Dans les limbes de graminées, les membranes représentent une proportion croissant avec l'âge au cours des différents cycles (de l'ordre de 0,2 à 0,3 unité par jour), et leur composition subit une évolution régulière mais très limitée ; leur teneur en lignine n'augmente que dans de faibles proportions sauf au premier cycle. Cela rejoint les observations microscopiques selon lesquelles la lignification des limbes $s^{2}$ limite pendant longtemps aux tissus vasculaires, et n'infiltre les tissus voisins que tardivement (PIGDEN, I95I).

L'augmentation de la proportion des membranes avec 1'âge, peut s'expliquer par l'un ou plusieurs des mécanismes suivants : formation de limbes ou de tissus contenant plus de membranes, augmentation de la proportion des membranes dans les, feuilles ayant terminé leur élongation soit par épaississement soit, indirectement par suite de la diminution (translocation) de certains constituants cytoplasmiques. Pour estimer l'importance relative de ces facteurs, il faudrait étudier l'évolution des caractéristiques chimiques et microscopiques des différentes feuilles.

I a composition des membranes des gaines ne subit, elle aussi, qu'une évolution 
très limitée avec l'âge mais, à la différence des limbes, la proportion de ces membranes ne semble pas augmenter lors des cycles feuillus ; il est vrai que les gaines ne représentent alors qu'une faible proportion de la feuille.

c) Dans les tiges de légumineuses, la proportion des membranes augmente régulièrement avec l'âge au cours des différents cycles ; cet accroissement est dû, presque exclusivement, à l'augmentation des teneurs en cellulose et en lignine, la teneur en hémicelluloses n'augmentant que très peu. Par suite, la composition moyenne des membranes de la tige évolue : les proportions de cellulose et de lignine y augmentent au détriment de la proportion des hémicelluloses (fig. I).

En l'absence des données biochimiques ou microscopiques, il n'est pas possible de faire la part des deux mécanismes qui peuvent expliquer cette évolution, à savoir la formation de tissus nouveaux ayant des membranes en proportion plus élevée et composition différente, et la transformation des tissus en place. Ce dernier mécanisme, doit être le plus important car les entre-nœuds đe légumineuses ne comportent pas de méristèmes secondaires : ils ont une croissance limitée et leurs membranes doivent rapidement s'épaissir et se lignifier. Ainsi dans les tiges du trèfle violet étudiées par Drapal,a et al. (I947), la lignification augmente régulièrement avec l'âge ; elle commence dans le xylème à la base des tiges, gagne vers le haut et s'étend au parenchyme ligneux et au sclérenchyme; la partie supérieure de la jeune tige ne présente d'ailleurs pas de sclérenchyme. Cela explique les observations récentes de TILIEY (I96I), suivant lesquelles le coefficient de digestibilité in vitro (par la population microbienne du rumen), présente un gradient du haut vers le bas de la tige de luzerne : le coefficient de digestibilité de la partie supérieure (I 5 premiers centimètres) est élevé aussi bien dans la plante âgée (77) que dans la plante jeune et il est beaucoup plus faible dans les parties inférieures où il diminue avec l'âge.

L'évolution que nous avons observée pourrait donc être due en majeure partie au fait que les membranes des entre-nouds inférieurs s'épaississent par dépôt de cellulose et de lignine. Cela rejoint les observations de ThornBEr et NorTHCoTE (I96I), sur la différenciation des cellules cambiales et l'épaississement des membranes dans les bois de frêne et de bouleau : cet épaississement s'effectue par dépôt de cellulose et de lignine de telle sorte que la proportion d'hémicelluloses diminue très nettement lorsqu'on passe du cambium au bois tendre et, plus encore, au bois dur.

D'après le nombre limité d'échantillons que nous avons étudiés, il semble que la composition des membranes des tiges de graminées, subisse au cours de la croissance une évolution moins importante que chez les légumineuses; la teneur en lignine de ces membranes augmente au détriment, surtout, de la teneur en hémicelluloses, mais leur teneur en cellulose ne semble pas présenter d'évolution très nette. A l'inverse des tiges de légumineuses qui ont une croissance apicale, les tiges de graminées s'allongent par le fonctionnement de méristèmes secondaires situés à la base des entrenœuds. Le degré de maturation mesuré par la résistance mécanique à la section augmente de la base au sommet de chaque entre nœud de la tige de seigle en croissance (PRAT, I935); il diminue d'un entre-nœud à l'autre de la base au sommet mais est cependant plus élevé dans l'entre-nœud terminal que dans 1'entre-nœud subterminal. Ces observations confirment celles d'ATHANASSOFF (I927), mais ne sont pas en complet accord avec celles de STEPPLER (I95I)selon lesquelles la proportion de tissus lignifiées est plus élevée au sommet qu'à la base des tiges de fléole et de brome inerme.

En définitive, la composition morphologique caractérisée par les proportions 
relatives de feuilles et de tiges, est le facteur prépondérant de la teneur de la plante entière en constituants membranaires. Son action est renforcée par le fait qu'avec l'âge, la teneur en membranes et, à un moindre degré, la composition de celles-ci, présentent une évolution plus importante dans les tiges que dans les feuilles, surtout chez les légumineuses. On peut considérer que les membranes des limbes foliaires ont une composition relativement peu variable, tout au moins aux stades où les plantes fourragères étudiées sont normalement exploitées. La composition des membranes de la plante entière évolue donc arec l'âge en même temps que la proportion des membranes augmente.

\section{LES DIFFÉRENCES ENTRE FAMILLES, ESPÈCES ET VARIÉTÉS}

Pour comparer de façon satisfaisante les membranes d'espèces fourragères différentes, il faut étudier pour chacune de celles-ci, un nombre suffisant d'échantillons de feuilles, de tiges ou de plantes entières, prélevées à des stades de développement comparables.

C'est ce que nous arons fait pour des espèces telles que la luzerne, le trèfle blanc, le ray-grass anglais, le dactyle et le chou, de telle sorte que les données obtenues nous permettent d'avancer quelques conclusions quant à l'influence de l'espèce, de la famille et parfois de la variété, sur la composition des membranes.

\section{Familles}

Entre les graminées et les légumineuses que nous avons étudiées, il apparaît des différences importantes dans la teneur et daus la composition des membranes, lorsqu'on compare les organes correspondants, d'âge équivalent, ou des plantes entières de mêne composition morphologique.

Les membranes des limbes de graminées contiennent beaucoup plus de xylanes et de cellulose vraie que celles des feuilles de légumineuses, mais moins d'hexosanes hydrolysables et, probablement moins de lignine (cette différence devant être cependant très atténuée lorsqu'on tient compte des acides uroniques dans l'estimation des membranes). De même, les membranes des tiges de graminées contiennent beaucoup plus de xylanes que celle des tiges de légumineuses, mais sensiblement moins d'hexosanes hydrolysables et de lignine (et aussi d'arabanes) ; en revanche, elles ont des teneurs en cellulose très voisines.

La proportion des membranes est nettement plus élevée dans les limbes de graminées que dans les feuilles de légumineuses même en tenant compte des acides uroniques, la différence s'accroissant avec l'âge. Elle est en revanche du même ordre dans les tiges des deux familles.

Ces résultats expliquent les différences dans les teneurs en constituants membranaires observées entre les deux familles, lorsqu'on compare des plantes entières à teneur en membranes égale (fig. 5 à II - tableaux 8 et 9). La luzerne contient toujours beaucoup moins de xylanes et d'hémicelluloses, et plus de lignine, que les graminées et, généralement, un peu plus de cellulose.

Lorsque la teneur en membranes augmente, ces différences s'accroissent pour les xylanes, les hémicelluloses et la cellulose, mais non pour la lignine. Il est intéressant 
de noter que celle-ci augmente sensiblement à la même vitesse dans les différentes catégories d'échantillons : les coefficients de regression ont été de $0,2 \mathrm{I}-0,2 \mathrm{I}-0,2 \mathrm{I}$ et $0, \mathrm{I} 7$ - respectivement pour la luzerne, le trèfle blanc, le ray-grass anglais $\mathrm{S} 24$ et le dactyle S 37 . Toujours à teneur en membranes égale, le trèfle blanc contient plus de lignine et moins d'hémicelluloses que les graminées.

\section{Espèces}

Par opposition aux profondes différences observées entre les graminées et les légumineuses, il existe une grande similitude dans la composition des membranes entre les espèces, à l'intérieur de chacune de ces deux familles, lorsqu'on compare des organes correspondants ou des plantes entières de même composition morphologique.

Ainsi, la proportion de cellulose est également faible dans les membranes des feuilles de luzerne et de trèfles. De même, les membranes des huit espèces de graminées récoltées à la floraison du I ${ }^{\text {er }}$ cycle en $\mathrm{I}_{95} 8$ (tableau $\mathrm{I}_{4}$ à $\mathrm{I} 7$ ) ont une composition très comparable, sauf en ce qui concerne les inflorescences. Mieux, les proportions relatives des différents polysaccharides membranaires dans les tiges de ces graminées fourragères (tableau 5), sont très voisines de celles observées dans les pailles de céréales par GAILIARD (I958b) (tableau I). Cette similitude doit traduire le fait que toutes ces graminées ont une structure microscopique comparable.

Il peut cependant exister entre espèces de la même famille, des différences limitées mais systématiques dans la composition des membranes, telles que celles que nous avons mises en évidence entre le ray-grass anglais S 24 et le dactyle S 37 , en analysant un nombre important d'échantillons de ces deux espèces qui ont été cultivées dans le même milieu (HURLEY), et récoltées à stade ou à âge comparables. Que ce soit à proportion de limbes égale ou à teneur en membranes égale, le dactyle S 37 a des membranes plus lignifiées mais plus pauvres en xylanes que le ray-grass $\mathrm{S} 24$. Cette différence ne semble pas être le fait de ces deux variétés, mais bien traduire une différence intrinsèque entre les deux espèces; elle existe en effet entre les autres échantillons des deux espèces que nous avons examinés, notamment lorsqu'on compare les gaines, limbes, tiges et même les inflorescences des deux espèces récoltées à la floraison de I958; le dactyle a même été la plus lignifiée des huit espèces examinées dans cette comparaison.

Ces variations de la composition des membranes doivent traduire des différences dans la proportion des différents tissus, plus spécialement dans l'importance relative des tissus conducteurs, des tissus de soutien (sclerenchyme) et des parenchymes, telles que celles qui ont déjà été observées entre les principales espèces de graminées (cf. Gain et BrocQ-Rousseu, I9I2 - St'teppi,ER, I95 - Pigdex, I953).

\section{Variétés}

Nous n'avons pas observé de différences dans la composition des membranes entre la luzerne de type Flamand et la luzerne du Poitou, pas plus qu'entre les choux de type moellier et les choux de type mille têtes. Ajoutées aux résultats sur la simili- 
tude entre espèces de la même famille, ces observations permettent de penser que les variétés d'une même espèce ont des membranes de composition très semblable, pour ne pas dire identique.

\section{ÉVOLUTION GÉNÉRALE DE LA COMPOSITION DES MEMBRANES}

Quand la proportion de membranes augmente d'une catégorie d'échantillons à l'autre (tableau 4), la composition de ces membranes présente une évolution plus ou moins régulière; les teneurs des membranes en cellulose vraie et en xylanes augmentent en moyenne, mais de façon irrégulière, en raison des différences entre familles; en revanche leur teneur en arabanes et, surtout, leur teneur en hexosanes hydrolysables diminuent de façon plus régulière. Ces variations, les dernières plus spécialement, ont une signification générale puisque nous les avions plus ou moins observées à l'intérieur de chaque catégorie d'échantillons. Elles permettent de faire quelques hypothèses sur la composition des membranes des différents tissus puisque l'augmentation de la proportion des membranes traduit l'augmentation de la proportion des tissus de soutien et de conduction par rapport aux parenchymes.

On peut ainsi penser que les membranes des parenchymes sont très riches en hexosanes hydrolysables et en arabanes et pauvres en xylanes. Cette hypothèse est à rapprocher des observations que nous avons effectuées par ailleurs sur cinq variétés de betteraves contenant de 8 à 25 p. Ioo de matière sèche : en moyenne leurs membranes ont représenté I I, 3 p. Ioo de la matière sèche et ont été très riches en arabanes $(32,4$ p. IOo) et très pauvres en xylanes $(3,8 \mathrm{p}$. roo). De même les membranes des coléoptiles d'avoine qui sont des membranes primaires contiennent autant de glusocane non cellulosique et autant d'arabanes que de xylanes (BIsHop et al., I958). A l'opposé les membranes des tissus de soutien et de conduction aux membranes épaisses seraient pauvres en hexosanes hydrolysables et en arabanes et riches en cellulose et en xylanes, ces derniers polysaccharides présentant des teneurs variables avec la famille botanique.

Quant à la teneur des membranes en lignine, elle ne présente pas d'évolution très nette quand l'importance des membranes augmente d'une catégorie d'échantillons à l'autre (surtout si on corrige les valeurs pour tenir compte des acides uroniques) alors qu'on aurait pu s'attendre à ce qu'elle augmente d'après les données microscopiques. Cela ne signifie pas cependant que les membranes des feuilles contiennent autant de lignine que celles des tiges, ni que celles des parenchymes en contiennent autant que celles des tissus de soutien et de conduction. Cela signifierait plutôt que la lignine, même corrigée, dosée dans les feuilles n'est pas la même que celle dosée dans les tiges et qu'elle est probablement " contaminée " par d'autres constituants. (cf. JOURNET et JARRIGE, Ig62).

Reçu pour publication en mars 1963

\section{SUMMARY}

THE CELL WALL CONSTITUENTS OF FODDER PLANTS

I) The object of this study was to obtain fundamental data on the contents of structural constituents of leaves, stems and whole plants of the main forage crops: lucerne, red clover, white clover, rye-grass, cocksfoot, kale... 
I 65 samples of separated organs, 82 samples of whole plants and 20 samples of meadow hays were analyzed, according to the scheme of JARRIGE (I96I), which includes the following treatments : water ; ethanol : benzene ; 5 per cent $\mathrm{H}_{2} \mathrm{SO}_{4} ; 72$ per cent $\mathrm{H}_{2} \mathrm{SO}_{4}$ ( +3 per cent $\mathrm{H}_{2} \mathrm{SO}_{4}$ ).

2) The reducing power $(\times 0,9)$ of hemicelluloses sugars in the 5 p. roo $\mathrm{H}_{2} \mathrm{SO}_{4}$ hydrolysate and of cellulose sugars in the $72 \mathrm{p} .100 \mathrm{H}_{2} \mathrm{SO}_{4}$ hydrolysate has been used to give a quantitative estimation of these substances. The crude lignin obtained was corrected for its crude protein content which was either measured directly, or estimated from the crude protein content of the sample (JOURNET and JARRIGE, I962).

The sugars in the hydrolysates of II4 representatives samples were separated by means of paper chromatography and measured by NELSON-SOMOGYI's colorimetric method. Xylose, arabinose and the sum glucose + galactose (hydrolysable hexosans) were measured in all the 5 p. IoO $_{2} \mathrm{H}_{2} \mathrm{SO}_{4}$ hydrolysates; xylose and glucose (true cellulose) were measured in all the 72 p. Ioo hydrolysates. Small quantities of other sugars were observed in some 5 p. Ioo hydrolysates (red clover - grasses at the flowering stage...) ; mannose was measured in all 5 p. 100 and 72 p. Ioo hydrolysates of leaves and stems of kale (table I9).

The polysaccharides have been calculated as anhydro sugars (as a percentage of the moisture free original sample), and the results are presented for each of the I 44 samples in tables I I-22. The hemicelluloses, cellulose and lignin contents of the 165 other samples are not presented individually. The average contents of each category of samples are presented in table 2 for the hemicelluloses, cellulose, lignin and membranes fractions (membranes $=$ hemicelluloses + cellulose + lignin), and in table 3 for total xylans, arabans, hydrolysable hexosans and true cellulose (72 p. Ioo glucosan) fractions.

3) There were considerable differences in the true cellulose content according to organs, stages of growth and family : from 9 p. Ioo in the leaves of legumes up to $30-35 \mathrm{p}$. I0o in most of the stems of grasses ans legumes cut at the flowering stage. The total xylans content was also very variable : from $2,5 \mathrm{p}$. 100 in lucerne leaves up to $18 \mathrm{p}$. Ioo on an average, in the heads of grasses. On the other hand the arabans content and the hydrolysable hexosans content were much less variable and were gererally between 3 and 4 p. Ioo, 2 and 3,5 p. Ioo respectively.

Quantitative relationships between the contents of the different constituents $(y)$ and the membranes content $(x)$ were studied for the main categories of whole plants (lucerne $\rightarrow$ rye-grass $\rightarrow$ cocksfoot). (tables 8 and $9-$ fig. 5-I I). The regression coefficients were between 0,35 and 0,65 for the cellulose content, 0,I4 and 0,44 for the hemicelluloses content, o, I 2 and 0,2 I for the lignin content, 0,22 and 0,42 for the xylans content. For a similar membranes content, the legumes contained more cellulose and lignin and less xylans and hemicelluloses than the grasses.

4) The contents of the different constituents were then expressed as a percentage of the membranes (sum hemicelluloses + cellulose + lignin) for studying the composition of these membranes and comparing samples which had very different membranes contents (table 4 ).

True cellulose ( 72 p. 100 glucosan) was always the main structural constituent of all the samples : on an average it represented $45 \mathrm{p}$. Ioo of the membranes of whole plants. Xylans were generally the most important polysaccharides after cellulose; their proportion in the membranes was very variable : from i $2 \mathrm{p}$. 100 in those of lucerne leaves up to $33 \mathrm{p}$. Ioo in those of the heads of grasses.

In all the species studied, the membranes in the leaves differed in composition from those in the stems. The contents of hemicelluloses, arabans and hydrolysable hexosans were higher in the membranes of leaves than those in the membranes of stems but the contents of xylans and cellulose were smaller. These differences were much less between the blades and stems of grasses than between the leaves stems of legumes, for which they increased with age. The membranes of the sheaths of grasses (table I 5 ) were more comparable in composition with those of blades (table $\mathrm{r}_{4}$ ) than with those of stems (table 16 ). The membranes in the heads of grasses (table 17 ) had a very high content of xylans and a relatively low content of cellulose.

The composition of the membranes in the leaves of legumes (table II and I2) and in the stems and leaves of kale (table 19) was approximately constant at different stages of growth. On the other hand, it showed an evolution with age in all the other samples studied; this evolution was very considerable in the membranes of the stems of legumes (figure $\mathrm{r}$ ) ; increases in lignin and cellulose contents were associated with corresponding decreases in the hemicelluloses, arabans and hydrolysable hexosans contents. This evolution was less pronounced in the stems of grasses and still less in the blades and the sheaths of grasses.

There were consistent differences between the legumes and the grasses in the composition of the membranes; the membranes in grass blades contained much more xylans and true cellulose but less hydrolysable hexosans and lignin than those in the leaves of legumes (table 4).

On the other hand, the composition of the membranes appeared to be very alike in species of the same family; however the membranes in $\mathrm{S} 24$ rye-grass contained significantly less lignin than those in $\mathrm{S} 37$ cocksfoot. 


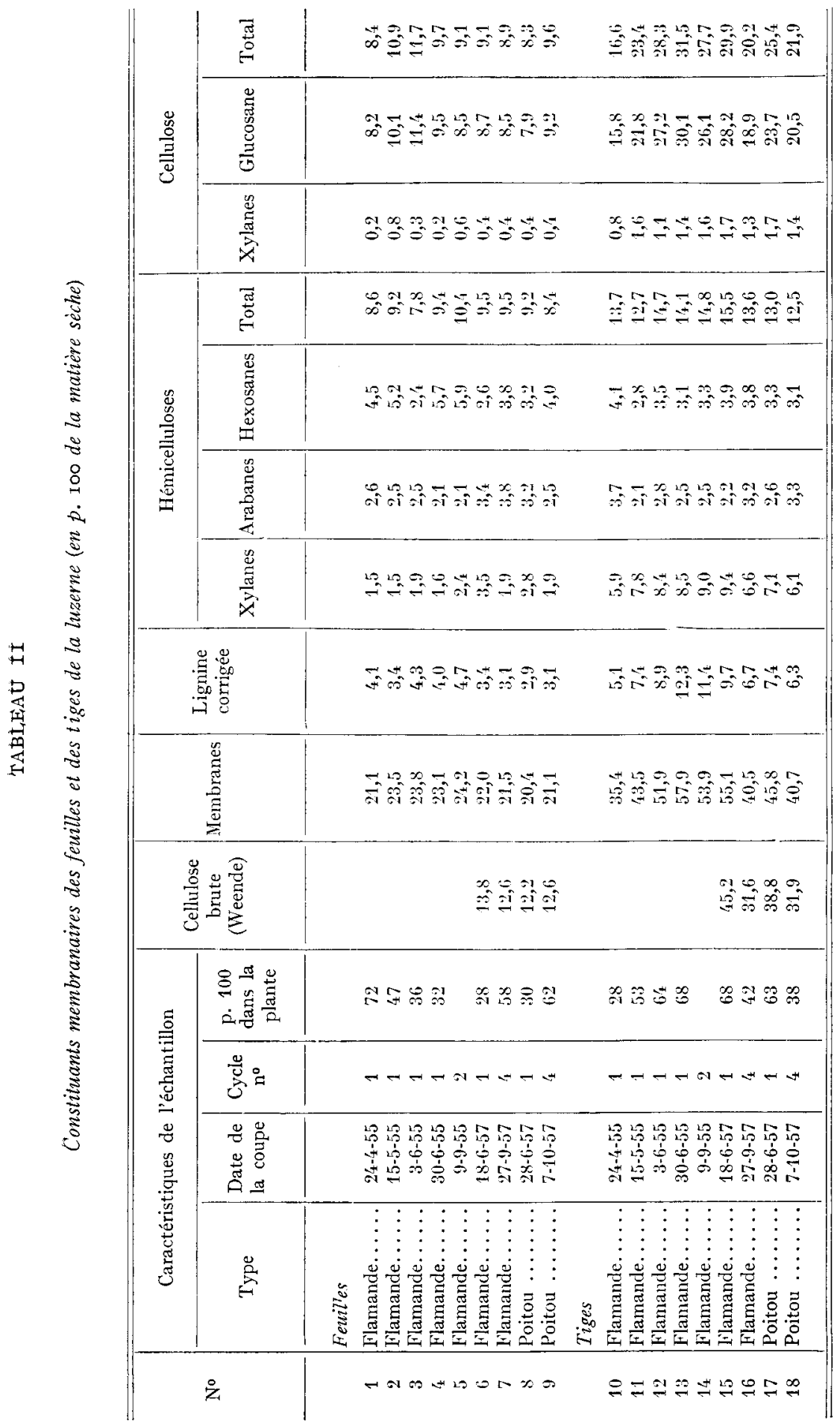




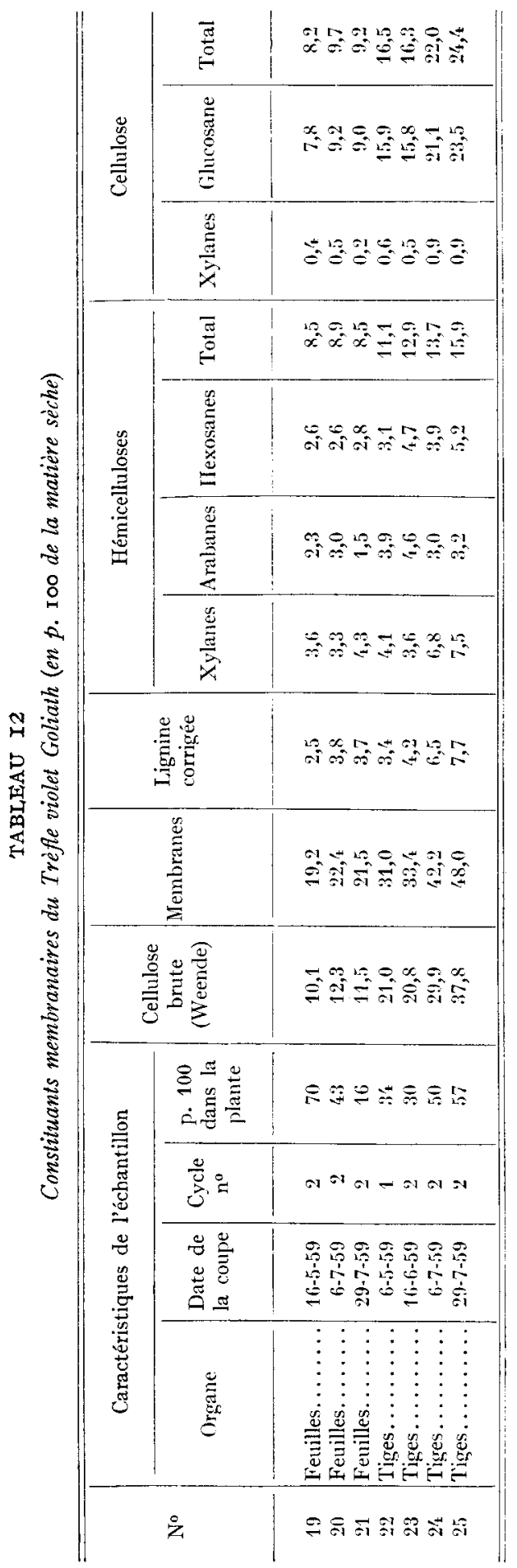

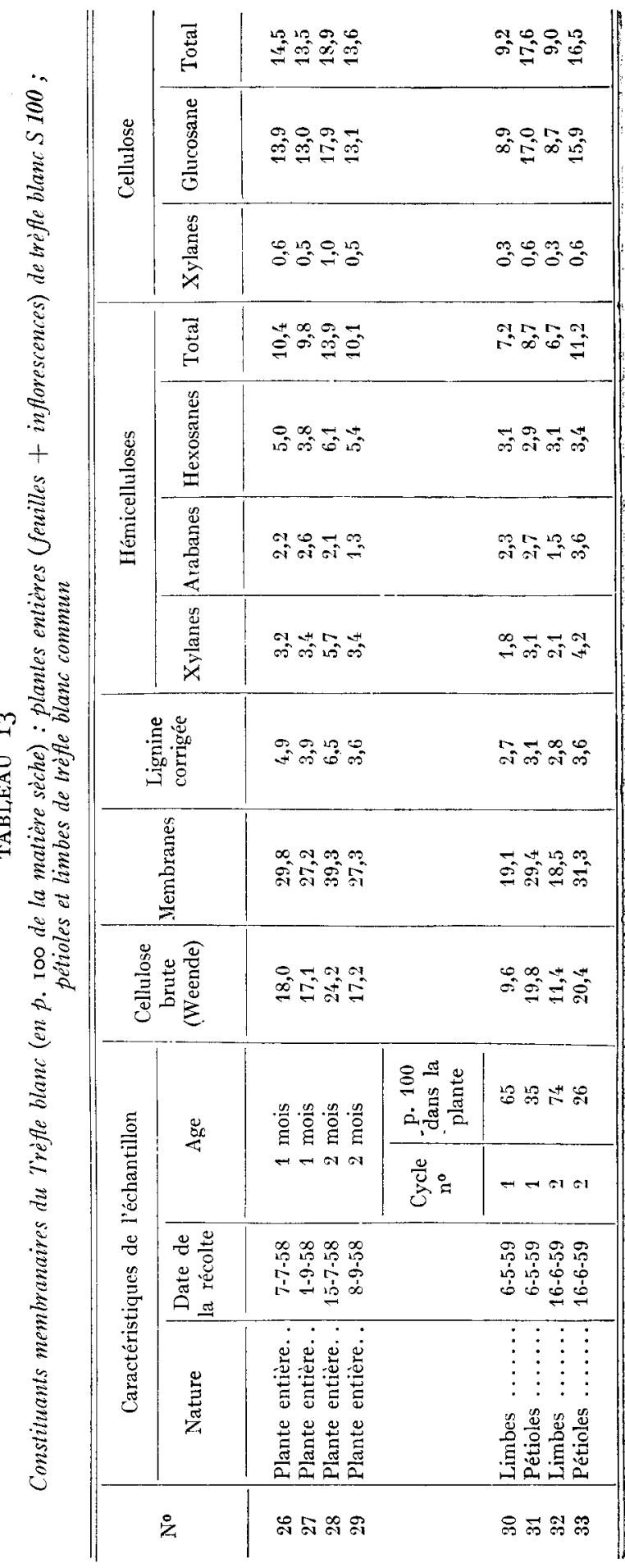



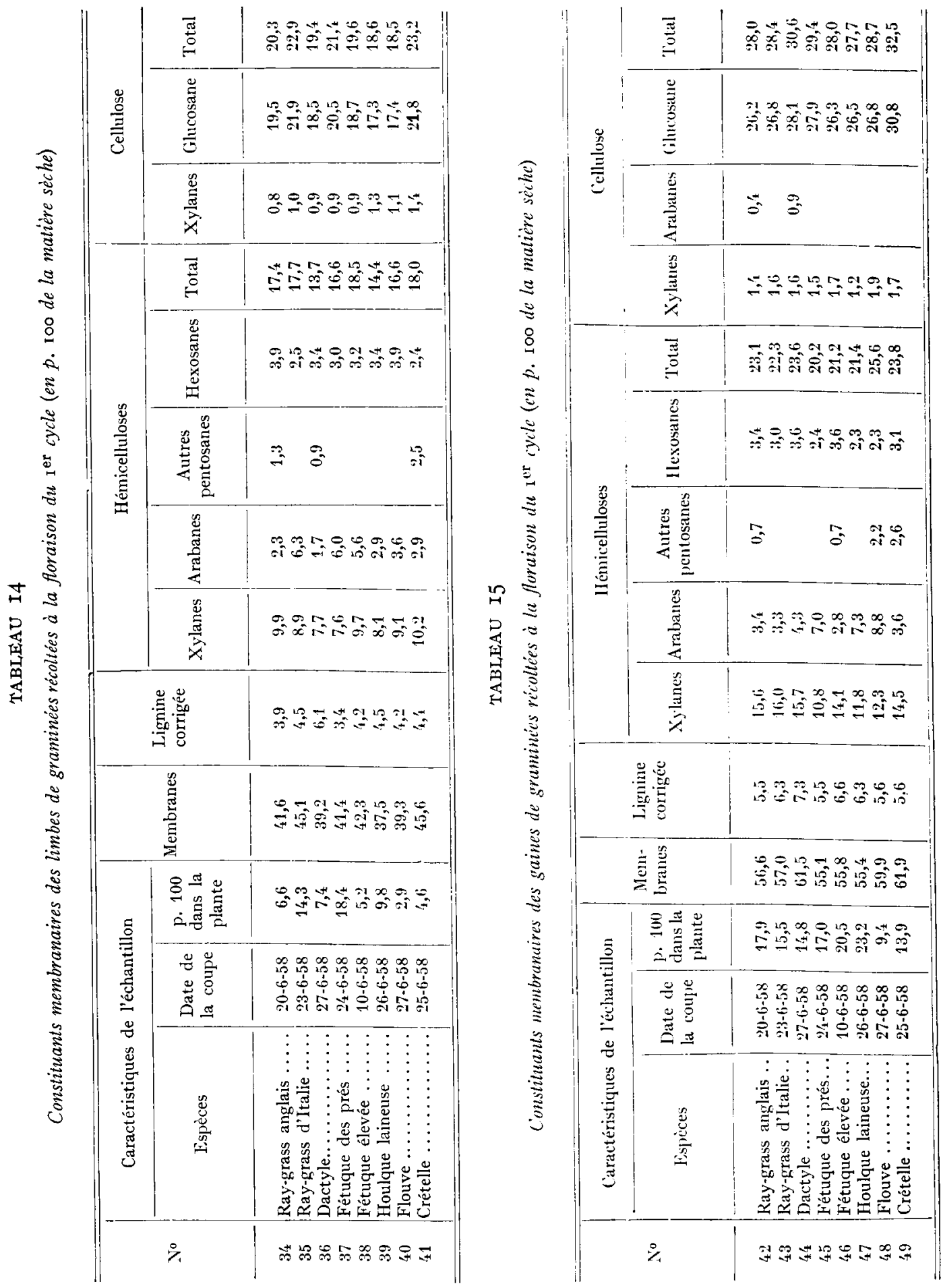


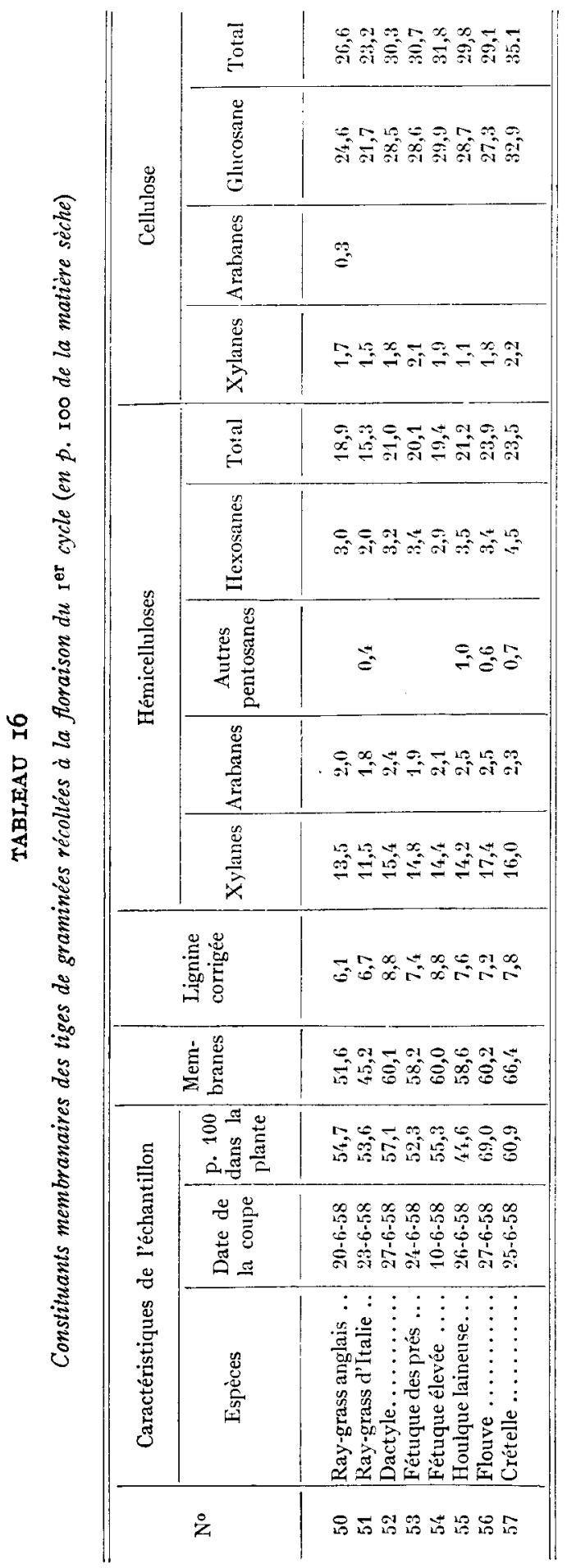

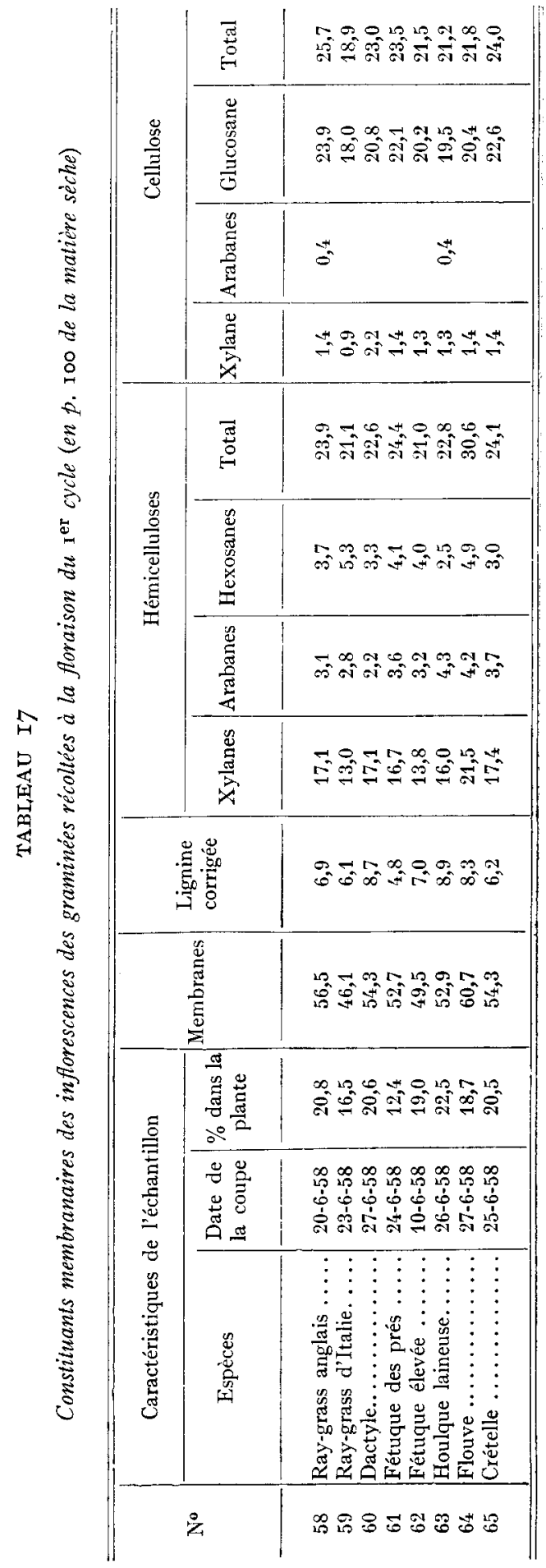




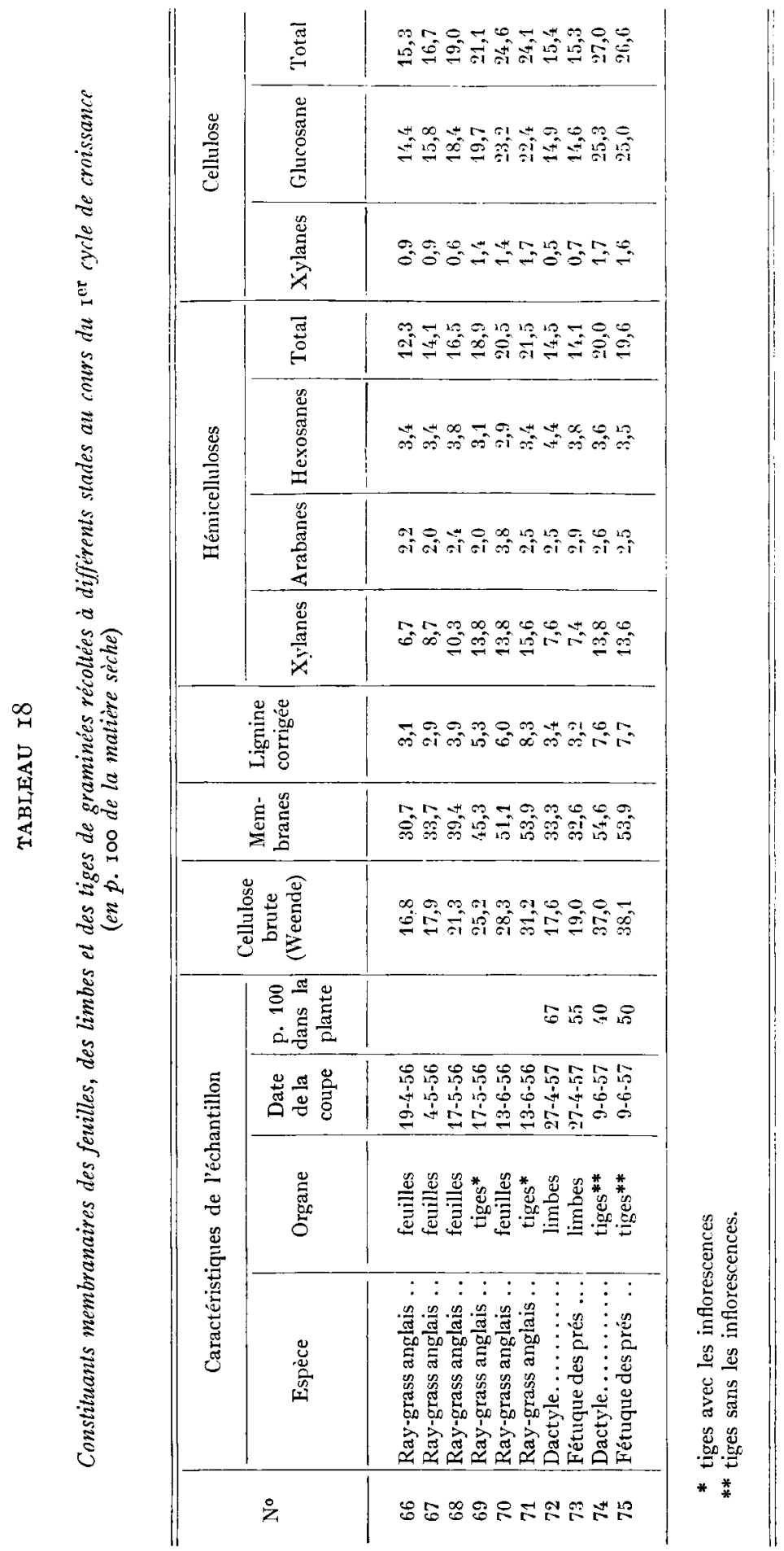


R. JARRIGE

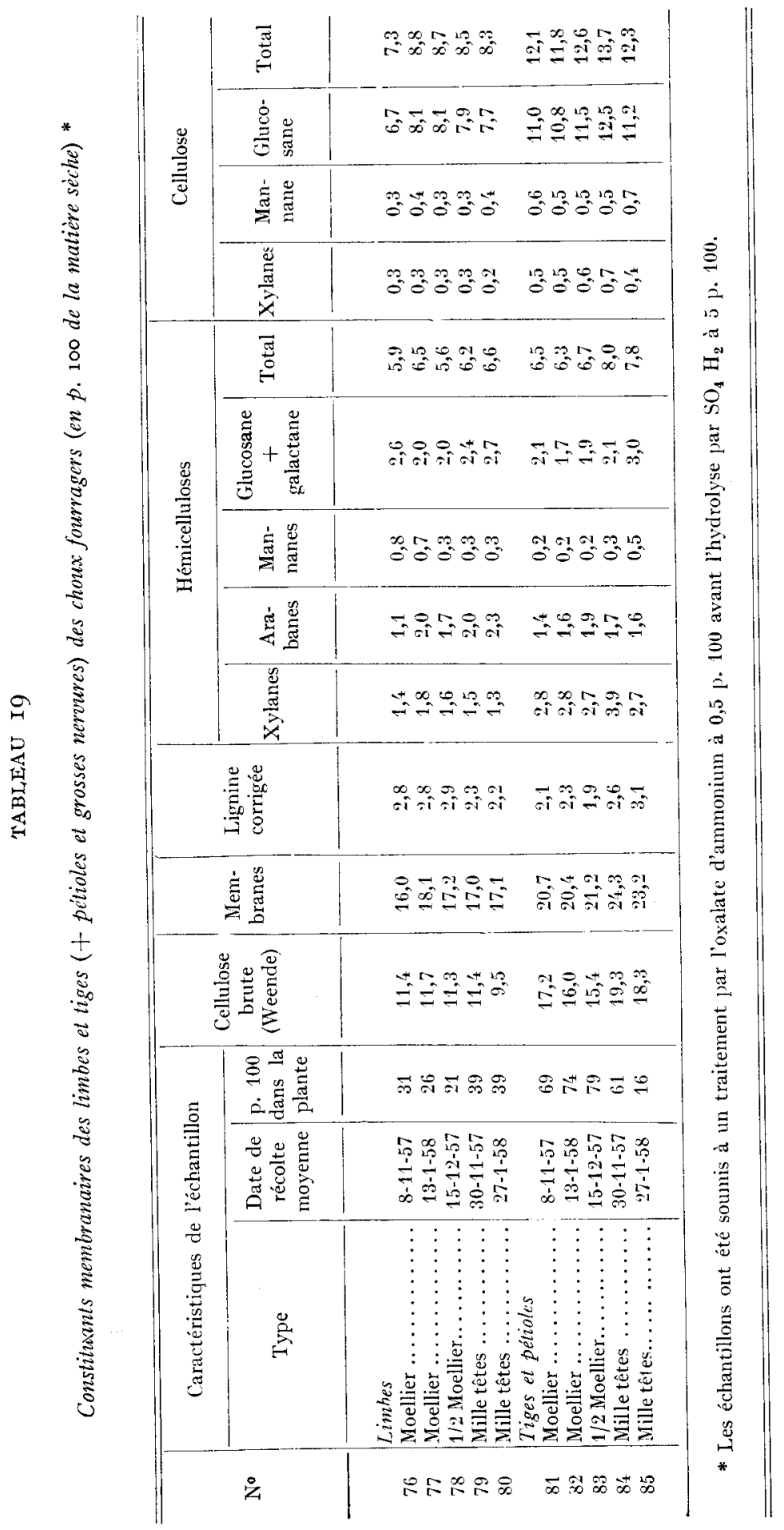



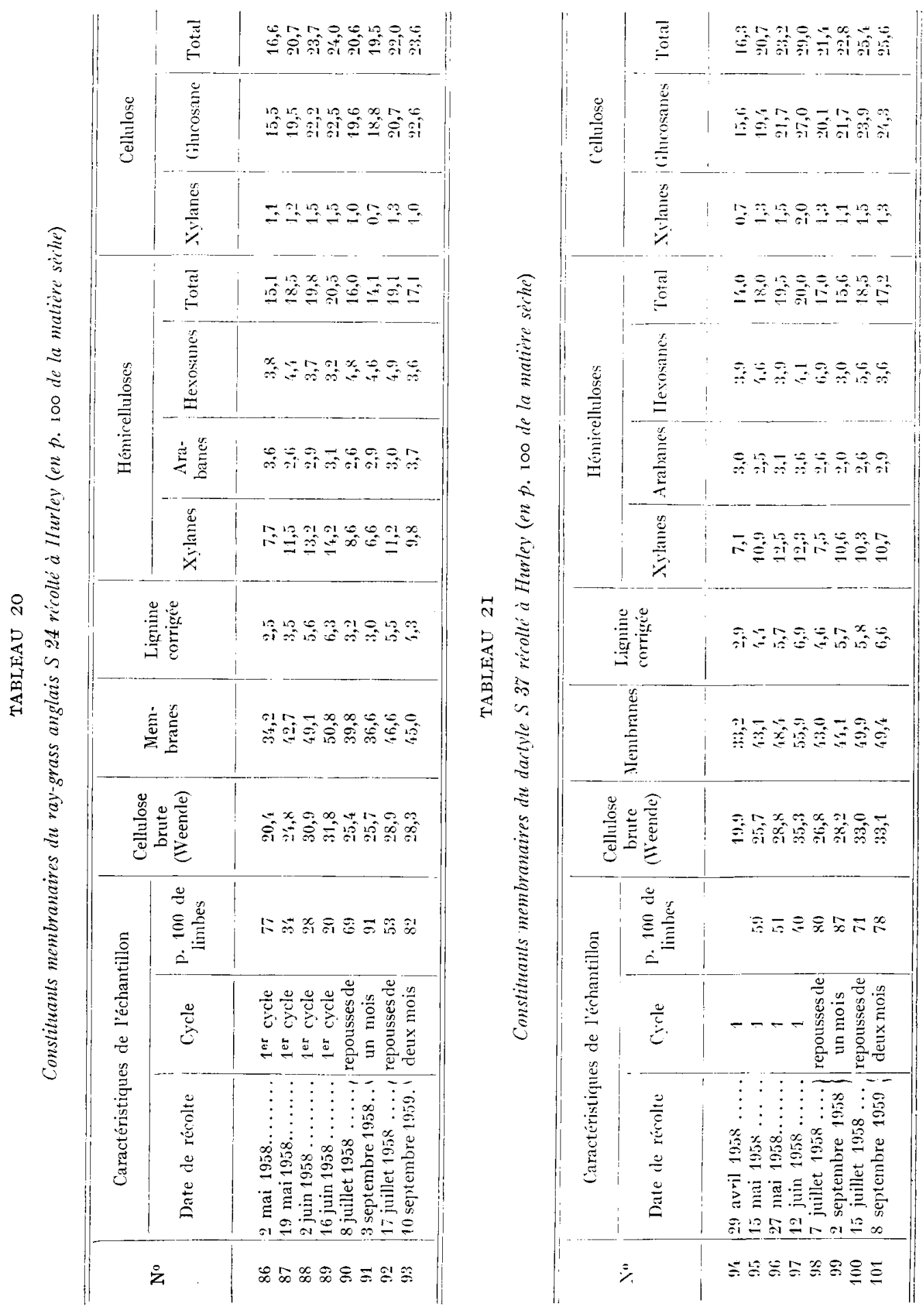

Annales de Biologie animale. - 1963. 


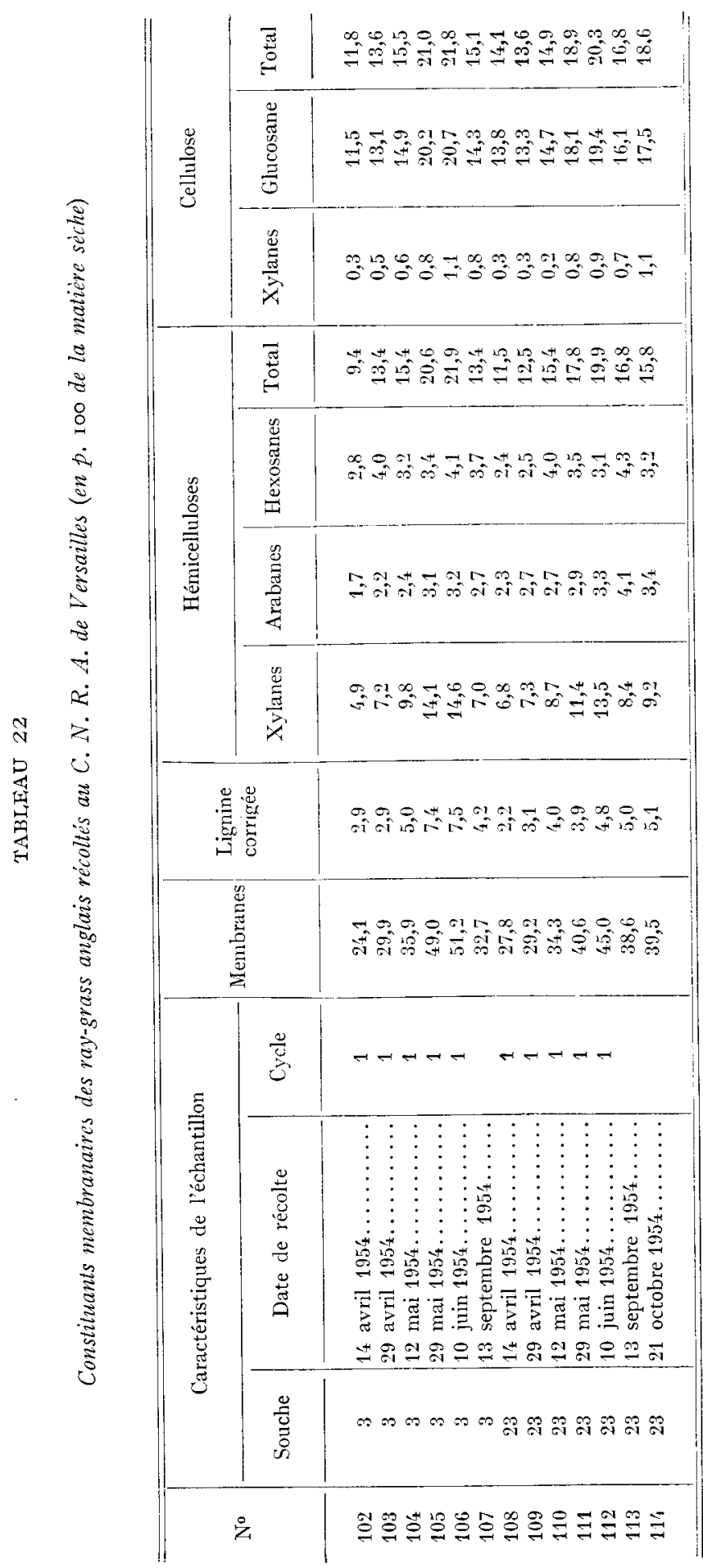




\section{RÉFÉRENCES BIBLIOGRAPHIQUES}

Armgstrong D G., Cook H., Thomas B., I950. The lignin and cellulose contents of certain grassland species at different stages of growth. J. Agric. Sci., 40, 93-99.

Athanajsoff A., I928. Anatomie et maturation des chaumes d'un pied de blé. Ann. Sci. Nat., Bot. Io Série, 10, I-Ior.

Baker C. J. L., Heimberg M., Alderman G., Eden A., 1952. Studies on the composition of sainfoin. $J$. Agric. Sci., 42, 382 .

Batн I. H., r960. Analysis of the structural carbohydrates of herbage. J. Sci. Fd. Agric., 11, 560-566.

Bishop C. T., Bayley S. T., Setterfield G., 1958. Chemical coposition of the primary cell walls of Avena coléoptiles. Plant physiol., 33, 283-289.

Buston H. W., 1934. The polyuronide constituents of forage grasses. Biochem. J. 28, 1028-1037.

Drapala W. J., Raymond L. C., Crampton W., r947. Pasture studies XXVII. Sci. Agr. 27, 36-41.

Fauconneau G., Jarrige R., 1955. Quelques problèmes physiologiques de l'utilisation des fourrages. C. $R$. des $5^{3}$ Journées d'étude de la F. E. Z. Reading). Pub. no 6 F. E. Z., I 2 I-I 42.

FERGUSON W. S., I948. Tha analysis of plant material with particular reference to structural constituents. Agric. Progr. 23, I $29^{-1} 37$.

Gaillard, BLANChe D. E., I958 $\mathrm{a}$. A datailed sum native analysis of the crude fibre and nitrogen free extractives of roughages. I. Proposed sch?m? of analysis. J. Sci. Fd. Agric., 9, I 70-1 77 .

GaILlaRD, BLANChe D. E., I958 $b$. A detailed sum native analysis of the crude fibre and nitrogen free extractives fractions of roughages.II. Th analysis of straw, hay, grass and mangold. J. Sci. Fd. Agric., $9,34^{6-}$ 353.

Gain E., Broç-Rousseu D., I9iz. Traité des foins. Baillière.

H.R WOOD V. D., I954. Analytical studies on the carbohydrates of grasses and clovers. V. Development of a method for the estimation of coll-wall polysaccharides. J.Sci. Fd. Agric., 5, 270-275.

Hirst E. L., Mackenzre D. K., Wylay C. B., r959. Analytical studies on the carbohydrates of grasses and clovers. IX. Changes in carbohydrate composition during the growth of lucerne. J. Sci, Food. Agric., 10, 19-25.

Honв T., 1953. Chəmical com josition and digestibility of grassland crops. Acta Agric. Scand., 3, 1-32.

JARrige R., 1950. The mimisanz coastituents of herbage. Proc. 8th. International Grassland congress $628-635$.

JaRrige R., I96r. Analyse des constituants glucidiques des plantes fourragères. I. Fractionnement des membranes par les hydrolys ss acides. Ann. Biol. anim. Bioch. Biophys., 1, 163-2 I 2.

Jermy M. A., Isherwood F. A., I 949. Improvad separation of sugars on the partition chromatogram. Biochem. J., 44, 402-407.

Journet H., Jarrige R., I962. Analyse des constituants glucidiques des plantes fourragères. III. Études sur le dosage de la lignine. Ann. Biol. anim. Bioch. Biophys., 2, 223-250.

Kivimae A., 1959. Chemical composition and digestibility of some grassland crops. Acta Agri. Scand., 9, Sup. 142 p.

MaCkenzie D. J., Wylan C. B., 1958. Analytical studies on the carbohydrates of grasses and clovers. VIII. Changes in carbohydrate composition during the growth of perennial Rye grass. J. Sci. Fd. Agric., 8, $3^{8-45}$.

Minson D. J., Raymond W. F., Harris C. E., I860. Studies in the digestibility of herbage. VIII. The digestibility of $\mathrm{S}_{37}$ cocksfoot, $\mathrm{S} 23$ rye grass and $\mathrm{S} 24$ rye grass. J. Bril. Grassl. Doc., 15, I 74-18o.

Phillips M., Davis B. L., Weihe H. D., I942. Composition of the tops and roots of the timothy plant at successive stages of growth. J. Agric. Res., 64, 533-546.

PIGDEN W. J., I953. The relation of lignin, cellulose, protein, starch and ether extrait to the "curing " of range grasses. Sci. Agric., 33, 364-378.

Prat H., 1935. Recherches sur la structure et le mode de croissance des chaumes. Ann. Sci. Nal. Bot., 17, 81.

Salo, Maija-LiIsa, 1961. Datermination of carbohydrates in aminal foods as seven fractions. Maataloust. Aikakausk, 33, 32-38.

Setterfield G., B.yley S. T., ig6r. Structure and physiology of cell walls. Adv. plant Physiol., 12 $35^{-6 z 2 .}$

Somogyi M., i952. Notes on sugar determination. J. Biol. Chem., 195, 19-23.

Steppler H. A., I95I. Pasture studies (XXXI). Lignification studies with various grass species. Sci. Agric., 31, I-I 4.

Thornber J. P., Northcote D. H., ig6r. Changes in the chemical composition of a cambial cell during its differenciation into xylem and phloem tissue in trees. Biochem. J., 81, 449-455, 455-464.

TILley M .,1961. Études in vitro de la digestion des fourrages. Ann. Nutr. Alim., 15, 267-272.

Annales de Biologie animale. - I963. 
Waite R., Gorrod A. R. N., 1959. The structural carbohydrates of grasses. J. Sci. Fd. Agric., 10, 308317.

Waite R., Gorrod A. R. N., I959. The comprehensive analysis of grasses. J. Sci. Fd. Agric., 10, 317326.

Wilsie C. P., Hollovell E. A., 1948. Effect of time of cutting red clover on forage yields, seed setting and chemical composition. Iowa Agric. Exp. Stat. Res, Bull. $n^{\circ} 357,639-668$.

Woodman H. E., Evans R. E., I935. Nutritive value of lucerne. 4. The leaf stem ratio. J. Agric.Sci., 25, $578-597$. 